\title{
Heme oxygenase 1 protects human colonocytes against ROS formation, oxidative DNA damage and cytotoxicity induced by heme iron, but not inorganic iron
}

\author{
Nina Seiwert ${ }^{1,2,3}$, Sabine Wecklein ${ }^{1}$, Philipp Demuth ${ }^{3}$, Solveig Hasselwander ${ }^{1,7}$, Talke A. Kemper $^{4}$, Tanja Schwerdtle ${ }^{4,5}$,
} Thomas Brunner ${ }^{6}$ and Jörg Fahrer (10)

\begin{abstract}
The consumption of red meat is probably carcinogenic to humans and is associated with an increased risk to develop colorectal cancer (CRC). Red meat contains high amounts of heme iron, which is thought to play a causal role in tumor formation. In this study, we investigated the genotoxic and cytotoxic effects of heme iron (i.e., hemin) versus inorganic iron in human colonic epithelial cells (HCEC), human CRC cell lines and murine intestinal organoids. Hemin catalyzed the formation of reactive oxygen species (ROS) and induced oxidative DNA damage as well as DNA strand breaks in both HCEC and CRC cells. In contrast, inorganic iron hardly affected ROS levels and only slightly increased DNA damage. Hemin, but not inorganic iron, caused cell death and reduced cell viability. This occurred preferentially in non-malignant HCEC, which was corroborated in intestinal organoids. Both hemin and inorganic iron were taken up into HCEC and CRC cells, however with differential kinetics and efficiency. Hemin caused stabilization and nuclear translocation of Nrf2, which induced heme oxygenase-1 (HO-1) and ferritin heavy chain (FtH). This was not observed after inorganic iron treatment. Chemical inhibition or genetic knockdown of HO-1 potentiated hemin-triggered ROS generation and oxidative DNA damage preferentially in HCEC. Furthermore, HO-1 abrogation strongly augmented the cytotoxic effects of hemin in HCEC, revealing its pivotal function in colonocytes and highlighting the toxicity of free intracellular heme iron. Taken together, this study demonstrated that hemin, but not inorganic iron, induces ROS and DNA damage, resulting in a preferential cytotoxicity in non-malignant intestinal epithelial cells. Importantly, HO-1 conferred protection against the detrimental effects of hemin.
\end{abstract}

\section{Introduction}

Heme is an important iron source in human nutrition and occurs mainly in food of animal origin such as meat ${ }^{1}$. Heme $b$ is the most abundant heme, consisting of a protoporphyrin ring with a central iron $\left(\mathrm{Fe}^{2+}\right)$. As such, it is the prosthetic group of the oxygen transporter proteins

Correspondence: Jörg Fahrer (fahrer@chemie.uni-kl.de)

${ }^{1}$ Department of Toxicology, University Medical Center, Mainz, Germany

${ }^{2}$ Rudolf Buchheim Institute of Pharmacology, Justus Liebig University Giessen,

Giessen, Germany

Full list of author information is available at the end of the article

Edited by J.-E. Ricci hemoglobin and myoglobin ${ }^{2}$. The central iron is coordinated by four nitrogen atoms of the protoporphyrin backbone and a histidine residue of the globin, leaving one free ligand-binding site for oxygen ${ }^{2}$. Upon its dietary uptake, heme is liberated from myoglobin or hemoglobin due to the acidic $\mathrm{pH}$ in the stomach and the enzymatic proteolysis occurring in both the stomach and duodenum $^{3}$. Heme is then internalized into intestinal epithelial cells, which is likely mediated by a transporter called heme carrier protein 1 (HCP-1; also known as protoncoupled folate transporter or PCTF) ${ }^{4,5}$. In the cytosol, it is finally catabolized by the enzyme heme oxygenase- 1

\section{(c) The Author(s) 2020}

(c) (i) Open Access This article is licensed under a Creative Commons Attribution 4.0 International License, which permits use, sharing, adaptation, distribution and reproduction cc) in any medium or format, as long as you give appropriate credit to the original author(s) and the source, provide a link to the Creative Commons license, and indicate if changes were made. The images or other third party material in this article are included in the article's Creative Commons license, unless indicated otherwise in a credit line to the material. If material is not included in the article's Creative Commons license and your intended use is not permitted by statutory regulation or exceeds the permitted use, you will need to obtain permission directly from the copyright holder. To view a copy of this license, visit http://creativecommons.org/licenses/by/4.0/. 
(HO-1) to biliverdin, ferrous iron $\left(\mathrm{Fe}^{2+}\right)$ and carbon monoxide $(\mathrm{CO})^{6}$.

In recent years, the dietary uptake of heme iron has attracted great attention due to its involvement in the etiology of colorectal cancer $(\mathrm{CRC})^{7}$. Heme occurs abundantly in red meat ${ }^{8}$, whose consumption has been classified as possibly carcinogenic to humans by the International Agency for Research on Cancer ${ }^{9}$. Several lines of evidence indicate that heme iron is the critical constituent of red meat driving colorectal tumorigenesis. The underlying mechanisms are not fully understood, but include intestinal hyperproliferation ${ }^{10,11}$, changes in the gut microbiota ${ }^{12,13}$ and genotoxic effects triggered by heme iron ${ }^{14,15}$. Apart from that, it has been shown that dietary heme promotes lipid peroxidation and, thus, the formation of reactive aldehydes such as 4-hydroxynonenal $(4-\mathrm{HNE})^{16,17}$. Interestingly, fecal water obtained from heme-fed rodents or its constituent 4-HNE exhibited a higher toxicity in normal murine colon epithelial cells with wildtype APC as compared to pre-neoplastic cells bearing a mutated APC allele $\left(\mathrm{APC}^{\mathrm{Min} /+}\right)^{17,18}$. The cellular resistance to heme triggered cytotoxicity was mediated by key enzymes responsible for 4-HNE detoxification ${ }^{19}$ and by the activation of the transcription factor $\mathrm{Nrf}_{2}{ }^{20}$, which is known to be engaged by oxidative stress and electrophilic compounds ${ }^{21}$.

Surprisingly, the effects induced by heme iron have never been directly compared to that of inorganic iron in normal or transformed colonocytes, and it is still unclear whether heme iron or its cellular breakdown product ferrous iron is responsible for DNA damage and cytotoxicity. In this work, we studied the genotoxic and cytotoxic potential of heme iron versus inorganic iron in normal human colonic epithelial cells (HCEC), human CRC cells lines and murine intestinal organoids. Initially, the formation of reactive oxygen species (ROS) and induction of DNA damage was assessed. Next, the impact of both iron species on cell cycle progression, cell death induction and cell viability was monitored. Iron uptake in HCEC and CRC cells was measured by inductively coupled plasma mass spectrometry (ICP-MS) and, indirectly, via detection of HO-1 expression levels. Finally, we addressed the role of HO-1 in heme-triggered ROS formation, DNA damage and cytotoxicity in both HCEC and CRC cells using the HO-1 inhibitor zinc protoporphyrin (ZnPP) and siRNA mediated knockdown of HO-1.

\section{Results}

Heme iron, but not inorganic iron, promotes ROS production and oxidative DNA damage in HCEC and CRC cells

First, we investigated the production of ROS in HCEC and CRC cell lines in response to hemin $\left(\mathrm{Fe}^{3+}\right.$ protoporphyrin chloride) and ferric chloride $\left(\mathrm{FeCl}_{3}\right)$ treatment using flow cytometry (Fig. 1a-d). In HCEC, hemin caused a dose-dependent increase in ROS levels already $30 \mathrm{~min}$ after incubation, with $200 \mu \mathrm{M}$ hemin resulting in a 25 -fold induction as compared to control cells (Fig. 1a and Supplementary Fig. S1A). The dose-dependent ROS production by hemin further increased after $2 \mathrm{~h}$ and was still observed after $24 \mathrm{~h}$, albeit at reduced levels (Fig. 1c; Supplementary Figs. S1A and S2B). In contrast, ferric iron only slightly induced ROS formation independent of the incubation period (Fig. 1a, c and Supplementary Fig. S2B). Importantly, incubation of HCEC with ferrous iron $\left(\mathrm{FeSO}_{4}\right)$ had also no or little effect on cellular ROS levels (Supplementary Fig. S2A, B). In HCT116 CRC cells, hemin caused an up to 3-fold upregulation of ROS levels as compared to control cells after $30 \mathrm{~min}$ (Fig. 1b and Supplementary Fig. S1B), with generally weaker effects as seen in HCEC. ROS levels further increased over time at the highest hemin dose (Fig. 1d, Supplementary Figs. S1B and $\mathrm{S} 2 \mathrm{D}$ ). Interestingly, $\mathrm{FeCl}_{3}$ hardly affected basal ROS levels in HCT116 cells (Fig. 1b, d and Supplementary Fig. S2D). A comparable hemin-dependent increase in ROS generation was detected in Caco-2 CRC cells, in which $\mathrm{FeCl}_{3}$ led to a non-significant rise in ROS levels (Supplementary Fig. S1C). Furthermore, ROS formation was determined in HCT116 cells maintained under reduced oxygen levels similar to HCEC. As observed before, hemin increased ROS production in HCT116 cells in a dosedependent manner with slightly weaker effects as observed under standard culture conditions (Supplementary Fig. S2E).

We then set out to analyze the impact of hemin or $\mathrm{FeCl}_{3}$ on DNA damage induction using the alkaline Comet assay with or without the DNA glycosylase Fpg. This enzyme recognizes 8-Oxoguanine (8-oxoG) and catalyzes the excision of the damaged base via $\beta-\delta$ elimination, resulting in the generation of DNA single-strand breaks ${ }^{22}$. Hence, this setup allows for the detection of both DNA strand breaks and oxidative DNA damage (i.e., 8-oxoG). Hemin significantly induced DNA strand breaks after $2 \mathrm{~h}$ of incubation in both HCT116 and HCEC (Fig. 1e). Interestingly, the Fpg-modified alkaline Comet assay revealed a strong dose-dependent induction of oxidative DNA damage in both cell types (Fig. 1f). In turn, inorganic iron generated neither substantial levels of oxidative DNA lesions nor DNA strand breaks (Fig. Fig. 1e, f), which is in line with the lack of ROS production (Fig. 1). After $24 \mathrm{~h}$ of incubation, DNA strand break level returned to baseline levels except for HCEC treated with $100 \mu \mathrm{M}$ hemin (Supplementary Fig. S3A). Oxidative DNA damage was still observed after hemin treatment in HCT116 cells, although the levels were diminished as compared to those after $2 \mathrm{~h}$ (Supplementary Fig. S3B). In HCEC, a massive induction of oxidative DNA lesions was found at a dose of $100 \mu \mathrm{M}$ hemin. It is noteworthy that $\mathrm{FeCl}_{3}$ showed almost 

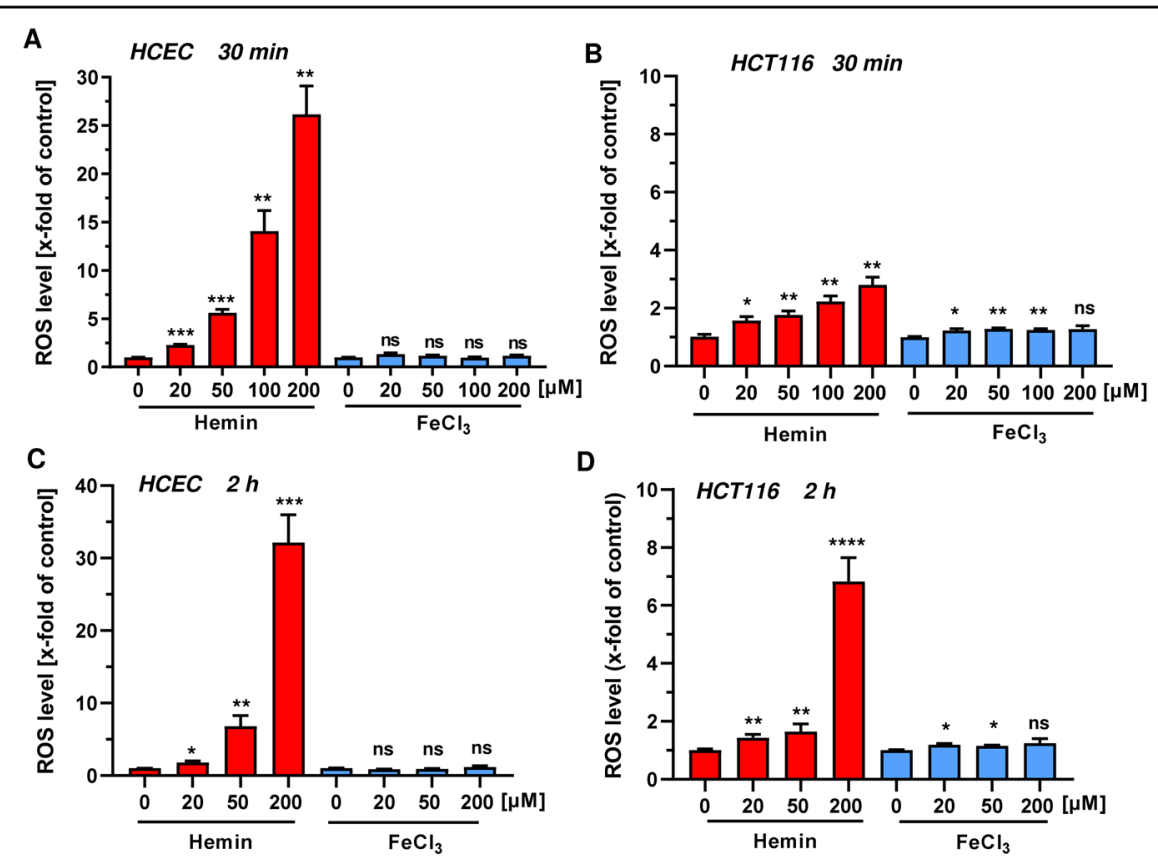

D
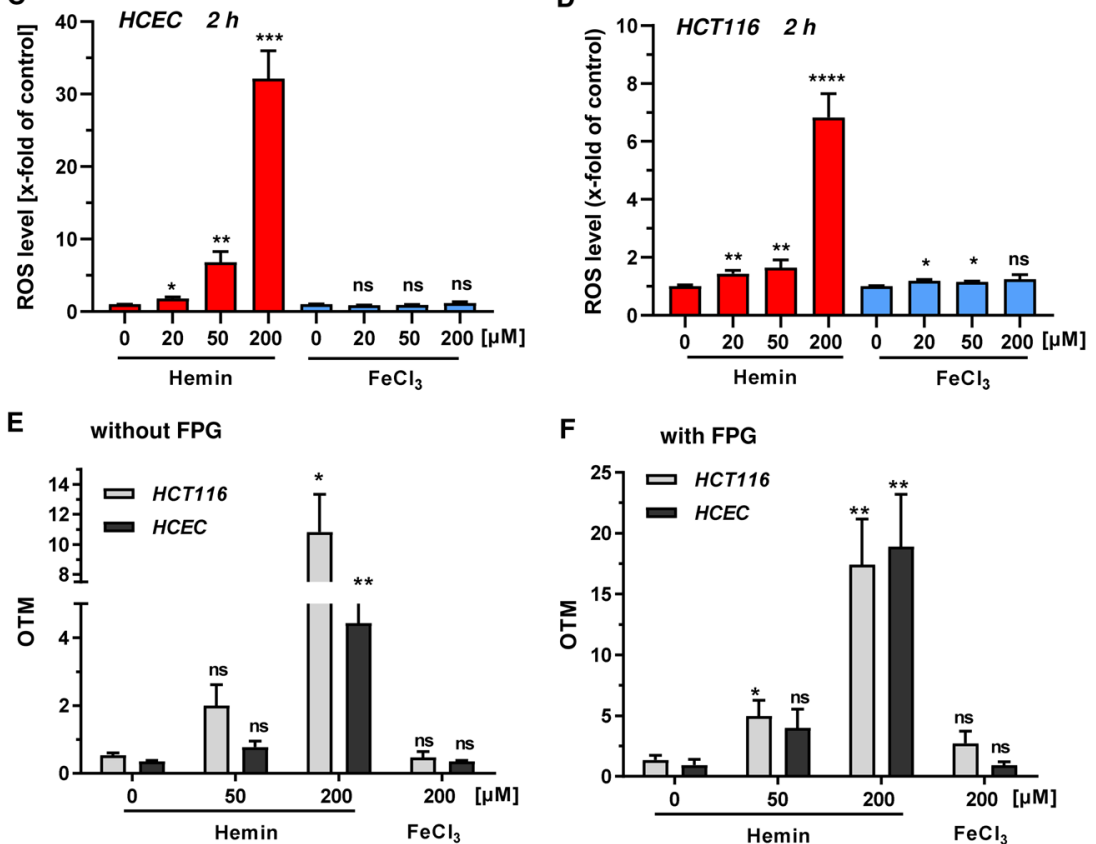

Fig. 1 Time-dependent formation of ROS and oxidative DNA damage in HCEC and CRC cells by heme iron versus inorganic iron. a, c HCEC were incubated for $30 \mathrm{~min}$ (a) or $2 \mathrm{~h}$ (c) with increasing doses of hemin or $\mathrm{FeCl}_{3}(0-200 \mu \mathrm{M})$. Reactive oxygen species (ROS) levels were assessed by live cell staining and subsequent flow cytometry-based analysis. b, d HCT116 were treated for $30 \mathrm{~min}$ (b) or $2 \mathrm{~h}$ (d) and analyzed as described under a. Data (a-d) is shown as mean + SEM ( $n \geq 3$, except for $20 \mu \mathrm{M}$ in HCT116 at $2 \mathrm{~h}: n=2)$. Ns: $p>0.05 ;{ }^{*} p<0.05$; ${ }^{* *} p<0.01$; ${ }^{* * *} p<0.001$, **** $p<0.0001$ (versus respective control). e, f Cells were exposed to hemin $(0-200 \mu \mathrm{M})$ or $\mathrm{FeCl}_{3}(200 \mu \mathrm{M})$ for $2 \mathrm{~h}$. DNA strand break induction and formation of oxidative DNA damage was determined by the alkaline Comet assay without (e) or with Fpg (f). Data are presented as mean + SEM ( $n \geq 3)$. Ns: $p>$ $0.05 ;{ }^{*} p<0.05 ;{ }^{* *} p<0.01$ (versus control).

no genotoxicity also after $24 \mathrm{~h}$ in both HCT116 cells and HCEC (Supplementary Fig. S3A, B). Furthermore, ferrous iron $\left(\mathrm{FeSO}_{4}\right)$ was not genotoxic in HCEC (Supplementary Fig. S3C). Taken together, our results demonstrate that hemin, in contrast to inorganic iron, generates ROS, DNA strand breaks and oxidative DNA damage in both normal HCEC and CRC cells.

\section{Heme iron, not inorganic iron, impairs viability} predominantly in HCEC and intestinal organoids

Having shown that hemin is genotoxic, its effects on cell viability were determined after $72 \mathrm{~h}$ using the MTS assay. Hemin led to a pronounced, dose-dependent reduction of viability in HCEC, reaching about $25 \%$ viability at $200 \mu \mathrm{M}$
(Fig. 2a). HCT116 cells were generally more resistant towards hemin treatment and showed only a moderate decrease in viability at the highest hemin dose (Fig. 2b). Caco-2 CRC cells also exhibited a lower sensitivity towards hemin than HCEC, with a viability of $60 \%$ at $200 \mu \mathrm{M}$ hemin (Fig. 2c). Interestingly, viability of HCEC and the CRC cell lines were only slightly reduced by inorganic iron (Fig. 2a-c and Supplementary Fig. S4E), consistent with its weak effects on ROS and DNA damage formation observed before. It should be noted that HCT116 and Caco-2 cells maintained under reduced oxygen tension $\left(7 \% \mathrm{O}_{2}\right.$ like $\left.\mathrm{HCEC}\right)$ displayed similar sensitivity towards hemin as compared to the standard culture conditions (Supplementary Fig. S4C, D). Further 

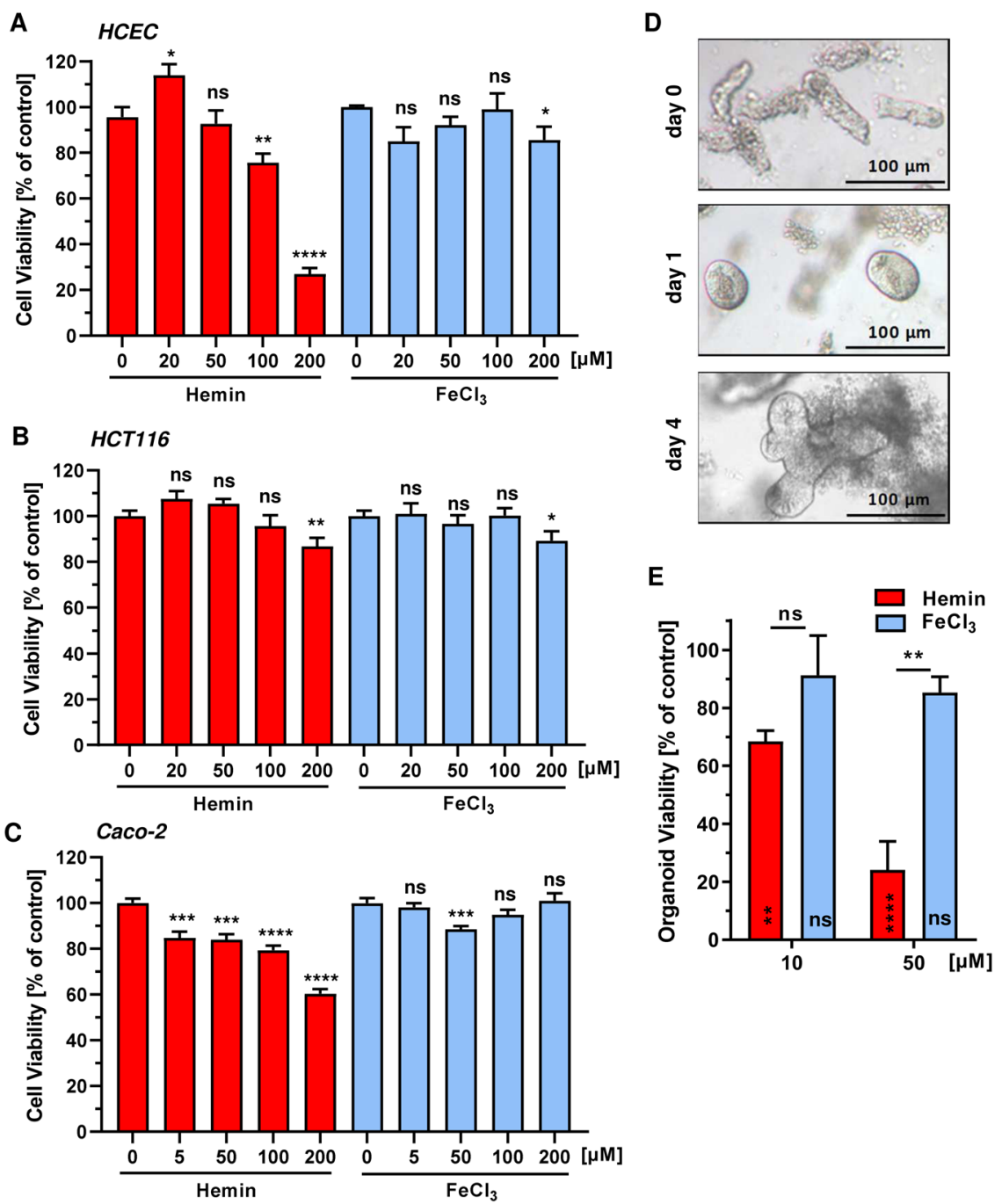

Fig. 2 Impact of heme iron and inorganic iron on cell and intestinal organoid viability. a-c HCEC (a), HCT116 (b) and CaCO-2 (c) were treated with increasing concentrations of hemin or $\mathrm{FeCl}_{3}(0-200 \mu \mathrm{M})$. Cell viability was determined after $72 \mathrm{~h}$ using the MTS assay. Data are given as mean + SEM ( $n \geq 3$, triplicates). Ns: $p>0.05 ;{ }^{*} p<0.05 ;{ }^{* *} p<0.01 ;{ }^{* * *} p<0.001$; ${ }^{* * *} p<0.0001$ (versus respective control). d Microscopic images of isolated intestinal crypts (day 0 ) and the developing intestinal organoids (day 1 and 4). e Intestinal organoids were treated with hemin or $\mathrm{FeCl}_{3}$ for $24 \mathrm{~h}$ and viability was determined by the MTT assay. Date are given as mean + SEM $(n=2)$. Ns: $p>0.05 ;{ }^{* *} p<0.01 ;{ }^{* * *} p<0.0001$.

experiments revealed that other CRC cell lines (RKO, LS174T) were also more resistant towards hemin than HCEC (Supplementary Fig. S4A, B). Taken together, heme triggered cytotoxicity was higher in HCEC as compared to the different CRC cell lines tested, while $\mathrm{FeCl}_{3}$ hardly affected viability in all cell lines. Finally, murine intestinal organoids were established to study the effects of hemin versus $\mathrm{FeCl}_{3}$ on their growth and viability (Fig. 2d). Hemin caused a substantial reduction in organoid viability already at $10 \mu \mathrm{M}$, with a further potentiation at $50 \mu \mathrm{M}$ (Fig. 2e). In contrast, $\mathrm{FeCl}_{3}$ only moderately decreased organoid viability, which closely mirrors the effects observed in HCEC (Fig. 2a, e). In conclusion, these findings provided evidence that hemin reduces viability predominantly in HCEC and intestinal organoids, while various CRC cell lines are only modestly affected. Moreover, inorganic iron displayed weak toxicity in all cell models and the intestinal organoids.

\section{Uptake kinetics of heme iron and inorganic iron into HCEC and CRC cells}

Next, we wished to know whether the cellular iron uptake might explain the observed differences between heme iron and inorganic iron on the one hand as well as HCEC and CRC cells on the other hand. To this end, cells were incubated with different hemin and $\mathrm{FeCl}_{3}$ concentrations for up to $24 \mathrm{~h}$. Cells were then harvested and analyzed for their total cellular iron content (both 

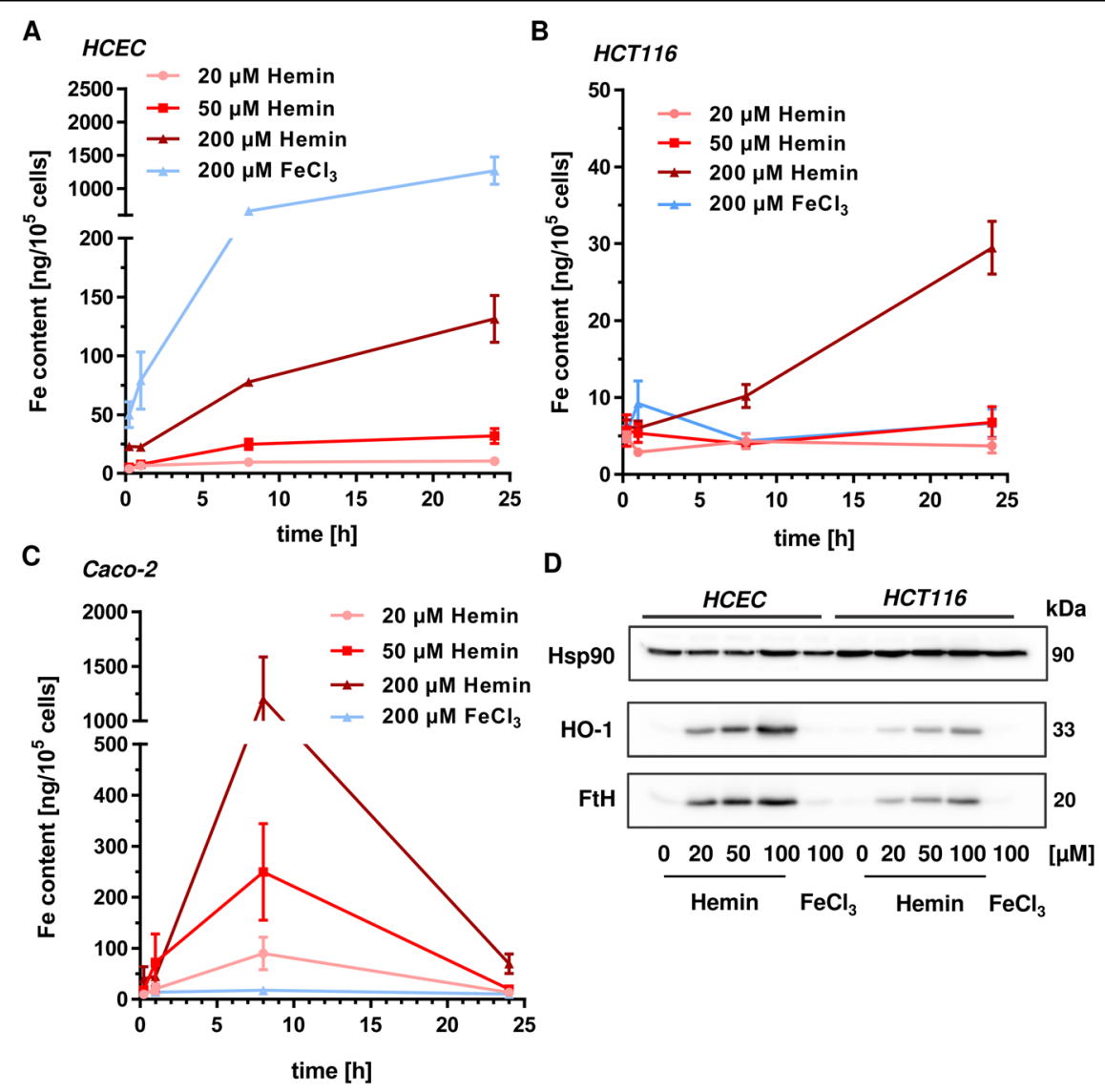

Fig. 3 Uptake of hemin and inorganic iron into HCEC and CRC cells. a HCEC were incubated with hemin or FeCl for different periods $(0,0.25,8$ and $24 \mathrm{~h}$ ) at the concentrations indicated. Cells were then collected and iron content was determined by ICP-MS as described. Data are depicted as mean + SEM $(n \geq 3)$. $\mathbf{b}$ HCT116 cells were treated with hemin or $\mathrm{FeCl}_{3}$ and iron content was analyzed as mentioned above. Data are shown as mean + SEM $(n=7)$. c Caco- 2 cells were treated and analyzed as described under a. Data are presented as mean + SEM $(n \geq 6)$. d HCEC and HCT116 cells were exposed to hemin or $\mathrm{FeCl}_{3}$ for $24 \mathrm{~h}$. Cells were harvested, lysed and subjected to Western blot analysis for heme oxygenase-1 (HO-1) and ferritin heavy chain gene $(\mathrm{FtH})$. Hsp90 was detected as loading control.

free iron and iron bound to proteins) using ICP-MS. First, the iron content was assessed in HCEC, revealing a time- and dose-dependent increase of the iron content following hemin treatment (Fig. 3a). After $24 \mathrm{~h}, 200 \mu \mathrm{M}$ hemin resulted in an iron content of $131 \mathrm{ng} / 10^{5}$ cells. Inorganic iron was internalized even more efficiently, with a maximum of $1200 \mathrm{ng}$ iron $/ 10^{5}$ cells after $24 \mathrm{~h}$ (Fig. 3a). In HCT116 cells, a time- and dose-dependent increase in cellular iron was detected upon hemin exposure, reaching a maximum Fe content $\left(\sim 30 \mathrm{ng} / 10^{5}\right.$ cells) after treatment with $200 \mu \mathrm{M}$ hemin for $24 \mathrm{~h}$ (Fig. 3b). Incubation with $200 \mu \mathrm{M} \mathrm{FeCl}{ }_{3}$ resulted in a maximum Fe content already after $1 \mathrm{~h}$, which then leveled out to about $7 \mathrm{ng}$ iron $/ 10^{5}$ cells after $24 \mathrm{~h}$. As observed in HCT116 and HCEC, hemin treatment resulted in a dosedependent increase of the cellular iron level in Caco-2 cells, with a maximum of $1200 \mathrm{ng} F \mathrm{Fe} / 10^{5}$ cells after $8 \mathrm{~h}$ (Fig. 3c). At the same time, incubation with $200 \mu \mathrm{M}$ $\mathrm{FeCl}_{3}$ raised cellular iron levels to $17 \mathrm{ng} / 10^{5}$ cells. As another readout for hemin uptake, the protein expression of HO-1 was analyzed in cell lysates form HCEC and HCT116 after 8 and $24 \mathrm{~h}$ (Fig. 3d and Supplementary Fig. $\mathrm{S} 5 \mathrm{C})$. HO-1 is responsible for the intracellular breakdown of hemin to ferrous iron, biliverdin and $\mathrm{CO}^{23}$. No or very little HO-1 induction was detected after $\mathrm{FeCl}_{3}$ treatment in both cell types. In opposition to that, hemin upregulated HO-1 expression in a dose-dependent manner, with stronger effects in HCEC than in HCT116 cells (Fig. 3d and Supplementary Fig. S5C). This is likely attributable to the better internalization of hemin into HCEC, resulting in up to 6-fold higher iron content as compared to HCT116 (Fig. 3a vs. 3b). Furthermore, a dose-dependent upregulation of ferritin heavy chain $(\mathrm{FtH})$ was observed after hemin exposure in both cell types, which was also more prominent in HCEC than in HCT116 cells and not induced by inorganic iron (Supplementary Fig. S5D, E). FtH and ferritin light chain (FtL) subunits assemble into the 24-mer ferritin (FTN), 

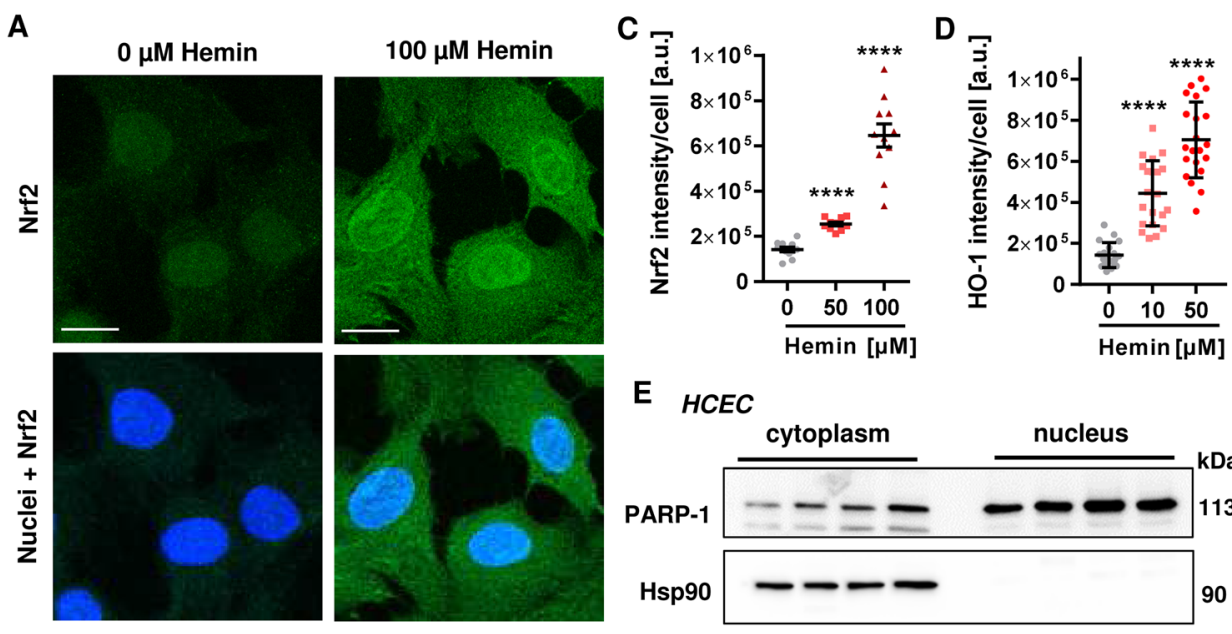

E HCEC
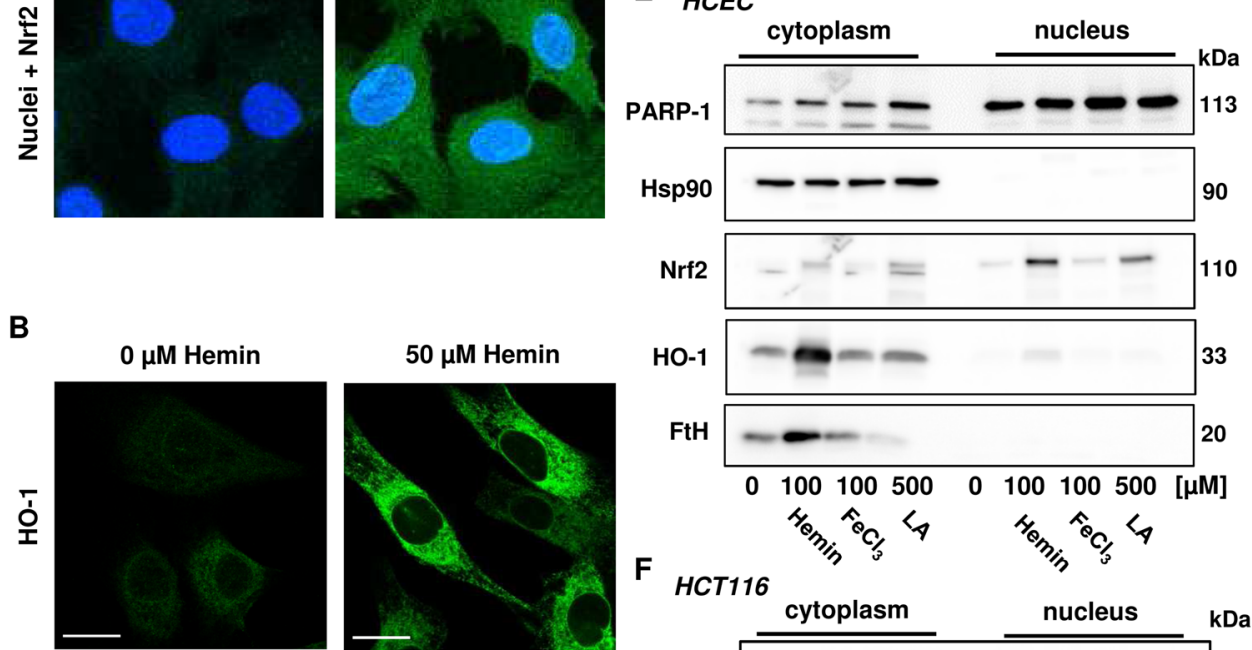

F
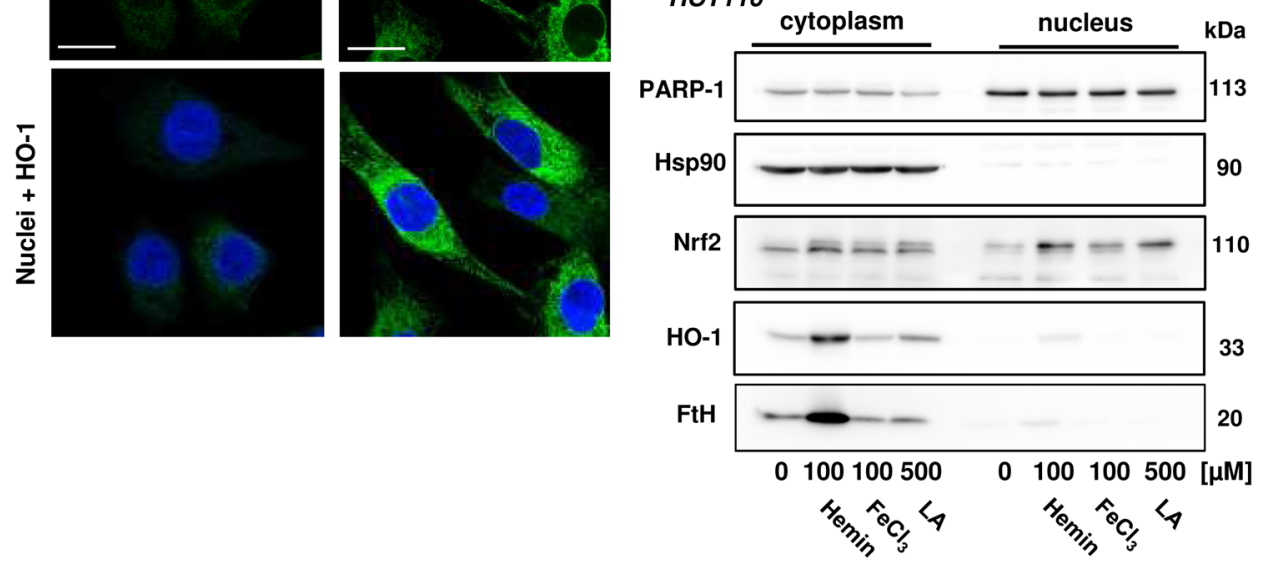

Fig. 4 Impact of hemin and inorganic iron on Nrf2 signaling in HCEC and CRC cells. a HCEC were exposed to hemin (0-100 $\mu \mathrm{M})$ for $2 \mathrm{~h}$. Cells were fixed, processed for Nrf2 staining and analyzed by confocal microscopy. Representative images are shown. Nrf2 is depicted in green and nuclei are shown in blue. Scale bar: $20 \mu \mathrm{m}$. b HCEC were treated with hemin $(0-50 \mu \mathrm{M})$ for $8 \mathrm{~h}$. Cells were fixed, processed for HO-1 staining and analyzed by confocal microscopy. Representative images are shown. HO-1 is depicted in green and nuclei are shown in blue. Scale bar: $20 \mu \mathrm{m}$. c Quantitative evaluation of Nrf2 staining shown in $\mathbf{a}$. Nrf2 intensity was quantified by ImageJ. Data are given as mean $+\operatorname{SEM}(n=2)$. ${ }^{* * * *} p<0.0001$. d Quantitative evaluation of HO-1 staining shown in $\mathbf{b}$. HO-1 intensity was quantified by ImageJ and data are indicated as mean + SEM $(n=3)$. ${ }^{* * * *} p<0.0001$. e HCEC were incubated for $8 \mathrm{~h}$ with $100 \mu \mathrm{M}$ hemin, $100 \mu \mathrm{M} \mathrm{FeCl}$, or $500 \mu \mathrm{M}$ a-Lipoic acid (LA). Cell fractionation was performed as described. Cytoplasmic and nuclear protein extracts were then analyzed by SDS-PAGE and western blot detection of Nrf2, HO-1 and FtH. PARP-1 served as nuclear loading control, while Hsp90 was used as cytoplasmic loading control. f HCT116 were treated, processed and analyzed as stated under e.

which is known to sequester free iron released by HO-1 mediated breakdown of heme ${ }^{24}$. In summary, heme iron and inorganic iron were taken up in a rather cell typedependent manner. Furthermore, the cellular iron contents seem not to directly correlate with the observed genotoxic and cytotoxic effects.
Hemin activates Nrf2 signaling and stimulates HO-1 expression in HCEC and HCT116 cells

We then analyzed the activation of the transcription factor Nrf2 by hemin. Nrf2 is a major player in the cellular response to oxidative stress, which results in its stabilization and translocation from the cytosol into the 
nucleus $^{25}$. Treatment of HCEC with increasing concentrations of hemin $(0-100 \mu \mathrm{M})$ for $2 \mathrm{~h}$ led to increased Nrf2 staining intensity and its accumulation in the nucleus as visualized by confocal microscopy (Fig. 4a, c and Supplementary Fig. S5A). Furthermore, HO-1 expression and its subcellular localization were studied, revealing a dose-dependent increase in $\mathrm{HO}-1$ intensity already detectable at $10 \mu \mathrm{M}$ hemin after $8 \mathrm{~h}$. As expected, HO-1 was detected almost exclusively in the cytoplasm of HCEC (Fig. 4b, d and Supplementary Fig. S5B). Moreover, the subcellular localization of Nrf2 and HO-1 was studied by Western blot analysis following cell fractionation. Consistent with confocal microscopy, hemin increased both Nrf2 and HO-1 levels in HCEC and promoted the accumulation of Nrf2 in the nuclear fraction. Likewise, hemin provoked $\mathrm{FtH}$ upregulation in the cytoplasm. In contrast, inorganic iron provoked modest Nrf2 induction without significantly upregulating $\mathrm{HO}-1$ or FtH (Fig. 4e). LA was included as a known activator of $\mathrm{Nrf}^{26}$, and thus caused Nrf2 stabilization with concomitant nuclear translocation. The lack of HO-1 induction by LA despite the observed Nrf2 activation is consistent with the notion that HO-1 induction by Nrf2 requires the inactivation of the transcriptional repressor $\mathrm{BACH}-1$ via heme binding $^{27,28}$. Similar effects were observed in HCT116 cells, although Nrf2 stabilization and particularly HO-1 expression were lower as in HCEC (Fig. 4f). Taken together, Nrf2 and its downstream target $\mathrm{HO}-1$ are rapidly induced by hemin, which preferentially occurred in HCEC.

\section{Chemical inhibition or genetic ablation of HO-1 potentiates hemin-triggered ROS and oxidative DNA damage}

In order to study the role of $\mathrm{HO}-1$ in cytoprotection and to figure out, which intracellular iron forms (hemin or inorganic iron produced by heme catabolism) are crucial for the geno- and cytotoxicity, we made use of the HO-1 inhibitor zinc protoporphyrin (ZnPP) that blocks heme breakdown ${ }^{29}$. First, hemin-triggered ROS formation was analyzed in HCEC in the presence or absence of ZnPP. The HO-1 inhibitor itself slightly elevated ROS levels, while $50 \mu \mathrm{M}$ hemin resulted in a pronounced increase in ROS (Fig. 5a and Supplementary Fig. S6A). Intriguingly, the combination of ZnPP and hemin strongly potentiated ROS formation, indicating that hemin itself is catalyzing ROS production (Fig. 5a and Supplementary Fig. S6A). Using the same experimental setup, almost no effects were observed in HCT116 cells (Fig. 5b and Supplementary Fig. S6B). To corroborate these results, HO-1 was downregulated by siRNA in both cell types (Fig. 5c). Treatment of HCEC with $50 \mu \mathrm{M}$ hemin caused a strong induction of HO-1 in untransfected cells or cells transfected with scrambled RNA, while HCEC with siRNA mediated HO-1 knockdown showed only very little induction (Fig. 5c, left panel). As expected, hemin provoked a robust upregulation of both Nrf2 and its downstream target $\mathrm{FtH}$ in HCEC independent of the HO-1 knockdown. In HCT116 cells, HO-1 knockdown prevented its induction by hemin, similar to HCEC (Fig. 5c right panel). The genetic abrogation of $\mathrm{HO}-1$ had no impact on $\mathrm{Nrf} 2$ and $\mathrm{FtH}$ induction following hemin treatment, both of which were however not as prominent as in HCEC (Fig. 5c). HO-1 knockdown moderately elevated basal ROS levels and strongly promoted ROS generation in HCEC upon hemin treatment (Fig. 5d and Supplementary Fig. S7A, B), which is in agreement with the results obtained with ZnPP (Fig. 5a). In HCT116 cells, siRNA mediated downregulation of HO-1 slightly increased basal ROS levels and potentiated ROS formation only in the presence of $200 \mu \mathrm{M}$ hemin (Fig. S7C, D), consistent with the findings obtained for $\mathrm{ZnPP}$ treatment (Fig. 5b). Afterwards, induction of DNA damage was studied using the alkaline Comet assay with Fpg modification. Single treatment of HCEC with the inhibitor already increased the level of oxidative DNA damage, which was particularly obvious at a dose of $1 \mu \mathrm{M} \mathrm{ZnPP}$ (Fig. 5e). Incubation with $50 \mu \mathrm{M}$ hemin caused only little DNA damage after $24 \mathrm{~h}$ as seen before (Fig. 5e and Supplementary Fig. S3). In the presence of the HO-1 inhibitor, both DNA strand breaks and oxidative DNA lesions were massively elevated as compared to the single treatments (Fig. 5e, f). Altogether, these findings strongly suggest that hemin, but not its cellular degradation product inorganic iron, is responsible for ROS generation and DNA damage induction.

\section{Inhibition or knockdown of HO-1 promotes hemin- triggered cytotoxicity}

Finally, we wished to know whether HO-1 inhibition by $\mathrm{ZnPP}$ affects cell cycle progression and viability in cells after hemin exposure. Hemin caused a dose-dependent increase in the subG1-population of HCEC, indicative of cell death (Fig. 6a and Supplementary Fig. S8A). HO-1 inhibition itself did not elevate the subG1-population as compared to the control, but increased the number of cells in G1-phase. Interestingly, combined treatment of HCEC with hemin and the HO-1 inhibitor strongly increased the subG1-population (Fig. 6a and Supplementary Fig. S8A). The cell cycle distribution of HCT116 cells was only significantly affected at a dose of $200 \mu \mathrm{M}$ hemin (Fig. 6b and Supplementary Fig. S8B). Treatment of HCT116 with the HO-1 inhibitor resulted in a moderate increase of cells in S-phase at the expense of a reduced G2/M-phase (Fig. 6b and Supplementary Fig. $\mathrm{S} 8 \mathrm{~B})$. In contrast to the findings in HCEC, $\mathrm{HO}-1$ inhibition did not augment the subG1-population induced by high hemin concentrations in HCT116, but rather shifted 

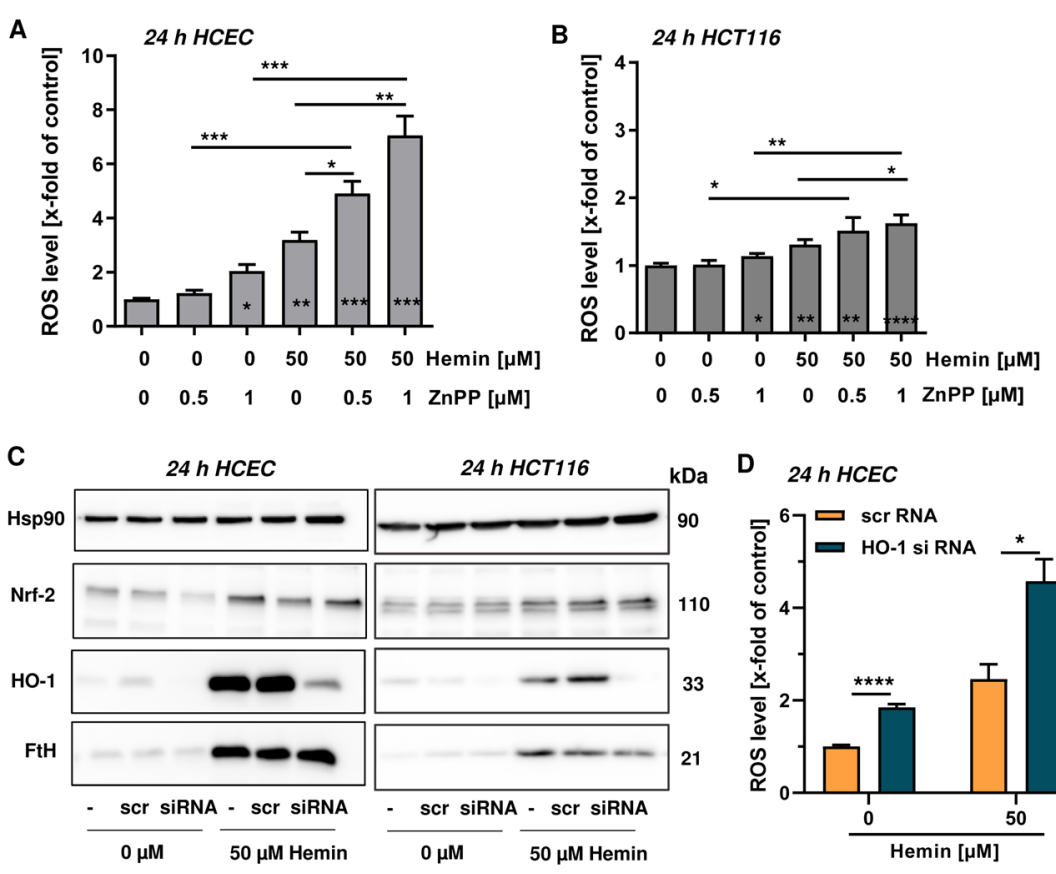

E 24 h HCEC

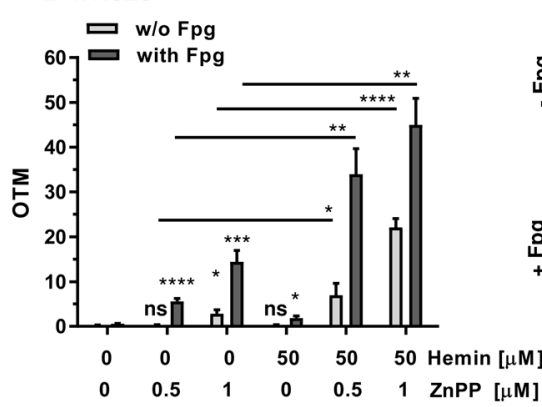

$\mathbf{F}$
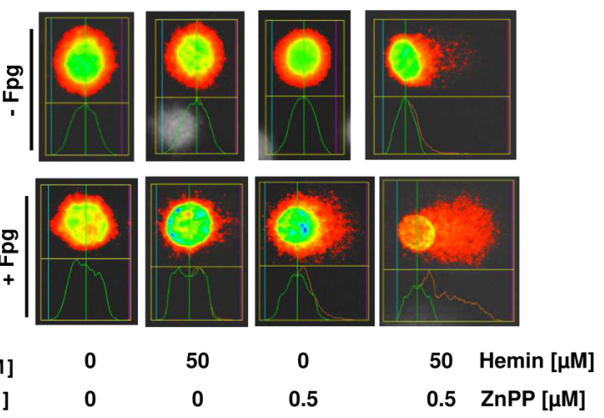

Fig. 5 Influence of HO-1 on hemin-triggered ROS and oxidative DNA damage in HCEC and CRC cells. a HCEC were incubated with hemin (0 or $50 \mu \mathrm{M}$ ) in the absence or presence of the HO-1 inhibitor zinc protoporphyrin ( $\mathrm{nnPP} ; 0.5$ or $1 \mu \mathrm{M}$ ) for $24 \mathrm{~h}$. Cells were stained with the CM-H2DCFDA dye and levels of reactive oxygen species (ROS) were assessed by flow cytometry. Data are presented as mean + SEM $(n \geq 3)$. ${ }^{*} p<0.05$; ${ }^{* *} p<0.01$; ${ }^{* * *} p<0.001$. b HCT116 cells were treated and analyzed as described above. Data are given as mean $+\operatorname{SEM}(n=4) .{ }^{*} p<0.05 ;{ }^{* *} p<0.01 ;{ }^{* * *} p<$ 0.0001. c HCEC and HCT116 cells were transiently transfected with scrambled (scr) or HO-1-specific siRNA. $24 \mathrm{~h}$ after transfection, cells were treated with hemin and incubated for another $24 \mathrm{~h}$. Whole-cell extracts were analyzed by SDS-PAGE and immunoblot detection of Nrf2 and FtH.

Hsp90 served as loading control, whereas HO-1 was visualized to confirm knockdown. d Knockdown of HO-1 in HCEC followed by hemin exposure for $24 \mathrm{~h}$ and analysis of ROS formation. ROS were measured by flow cytometry as stated above. Data are given as mean + SEM $(n=4) .{ }^{*} p<0.05$; ${ }^{* * * *} p<0.0001$. e HCEC were treated with hemin $(0$ or $50 \mu \mathrm{M})$ in the absence or presence of the HO-1 inhibitor ZnPP (ZnPP; 0.5 or $\left.1 \mu \mathrm{M}\right)$ for $24 \mathrm{~h}$. Cells were then subjected to the alkaline Comet assay with or without Fpg. OTM, olive tail moment. Data are given as mean $+\operatorname{SEM}(n=5)$. Ns: $p>0.05$; ${ }^{*} p<0.05 ;{ }^{* *} p<0.01 ;{ }^{* *} p<0.001,{ }^{* * *} p<0.0001$. $\mathbf{f}$ Representative pictures of the data shown in $\mathbf{e}$.

cells from S-phase to G2/M-phase (200 $\mu \mathrm{M}$ hemin vs. $200 \mu \mathrm{M}$ hemin $+\mathrm{ZnPP})$. Subsequently, cell viability was assessed using the MTS assay in both HCEC and HCT116 cells. The HO-1 inhibitor itself slightly improved viability of $\mathrm{HCEC}$, while treatment with $100 \mu \mathrm{M}$ hemin caused a significant reduction in viability (Fig. 6c). Intriguingly, the presence of the HO-1 inhibitor potentiated the hemindependent loss of viability in HCEC, which is in agreement with the findings described above. This was further confirmed using the ATP assay as endpoint, revealing strongly enhanced cytotoxicity if HO-1 dependent degradation of hemin is blocked using ZnPP (Supplementary Fig. S9A, B). Next, HO-1 expression was silenced by siRNA in both HCEC and HCT116 cells. Knockdown of HO-1 potentiated hemin-induced cytotoxicity in HCEC (Fig. 6e), which is in line with the experiments using the HO-1 inhibitor ZnPP (Fig 6a, c). In contrast to that, knockdown of HO-1 in HCT116 cells only moderately affected viability at $200 \mu \mathrm{M}$ hemin (Fig. 6f), confirming the results obtained with ZnPP treatment (Fig. 6b, d). In summary, the results highlight the cytoprotective role of HO-1 following hemin exposure and reveal that 

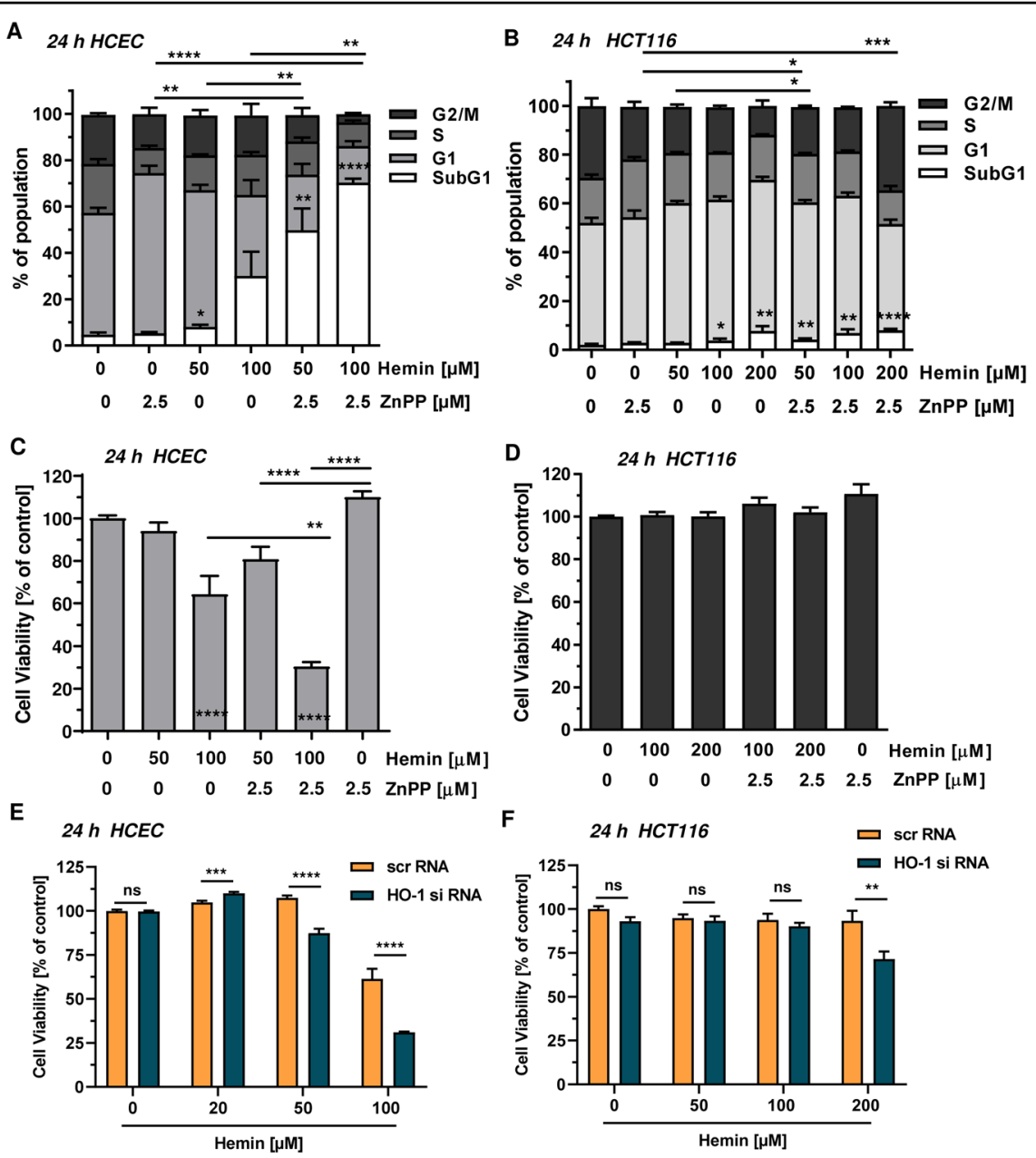

Fig. 6 Influence of HO-1 on hemin-triggered cell cycle distribution and cytotoxicity in HCEC and CRC cells. a HCEC were treated with hemin $(0-100 \mu \mathrm{M})$ in the absence or presence of the HO-1 inhibitor zinc protoporphyrin (ZnPP; $2.5 \mu \mathrm{M})$ for $24 \mathrm{~h}$ and collected for cell cycle analysis by flow cytometry. Data were evaluated by BD FACS Diva software and are shown as mean + SEM $(n=4)$. Statistical evaluation performed for subG1 population (white bars). ${ }^{*} p<0.05 ;{ }^{* *} p<0.01 ;{ }^{* * *} p<0.0001$. $\mathbf{b}$ HCT116 cells were treated and analyzed as described above. Data are given as mean + SEM $(n \geq 3) .{ }^{*} p<0.05 ;{ }^{* *} p<0.01 ;{ }^{* *} p<0.001 ;{ }^{* * * *} p<0.0001$. c HCEC were treated as described in a and cell viability was assessed using the MTS assay. Data are shown as mean + SEM $\left(n \geq 2\right.$, triplicates). ${ }^{* *} p<0.01 ;{ }^{* * *} p<0.0001 \mathbf{d}$ HCT116 cells were treated and analyzed as described in $\mathbf{a}$. Data are given as mean + SEM ( $n=2$, triplicates). e HCEC were transiently transfected with scrambled (scr) or HO-1-specific siRNA. $24 \mathrm{~h}$ following transfection, cells were treated with increasing hemin concentrations for another $24 \mathrm{~h}$. Cell viability was determined by the MTS assay. Data are shown as mean + SEM $\left(n=4\right.$, triplicates). Ns: $p>0.05 ;{ }^{* * *} p<0.001$, ${ }^{* * *} p<0.0001$. f HCT116 cells were transiently transfected with scrRNA or HO-1 specific siRNA. Further treatment and analysis as described under e. Data are shown as mean + SEM ( $n \geq 3$, triplicates). Ns: $p>0.05 ;{ }^{* *} p<0.01$.

hemin, but not its breakdown product inorganic iron, causes cytotoxicity. The major findings have been summarized in a scheme presented in Fig. 7.

\section{Discussion}

The present work compared the genotoxic and cytotoxic effects of hemin and inorganic iron side-by-side in HCEC versus CRC cell lines. First, we demostrated that hemin $(\geq 20 \mu \mathrm{M})$ caused substantial ROS formation in a concentration-dependent manner in both HCEC and CRC cells, whereas inorganic iron had only very little or no effects. Notably, this held true for both ferric and ferrous iron. In line with the latter finding, ferric iron added as ferric nitrilotriacetate (Fe-NTA) promoted ROS formation in HT29 CRC cells only at a very high dose of $1000 \mu \mathrm{M}^{30}$. Similarly, treatment of the hepatic cell line HH4 with ferric ammonium citrate resulted in signifcantly increased ROS levels only at concentrations above $1000 \mu \mathrm{M}$, while incubation of cells with $100 \mu \mathrm{M}$ ferric ammonium citrate or ferric chloride did not augment basal ROS levels ${ }^{31,32}$. In support of our results, another study also reported ROS generation in HCT116 and RKO cells treated with $100 \mu \mathrm{M}$ hemin ${ }^{33}$. Furthermore, we showed that hemin, in contrast to inorganic iron, caused DNA strand breaks as well as oxidative DNA damage (i.e., 8-oxoG) in HCEC and CRC cells. DNA 

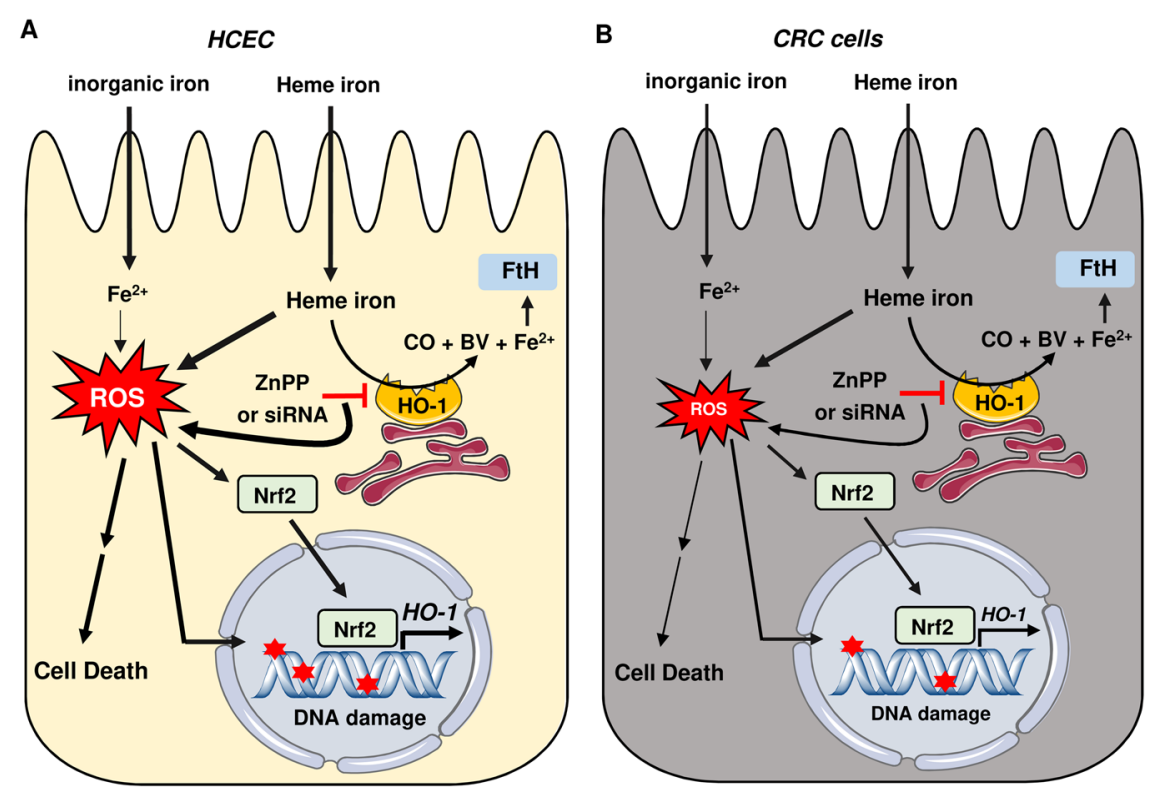

Fig. 7 Model of heme-triggered DNA damage and cytotoxicity in HCEC versus CRC cells and role of HO-1. a Heme iron is taken up into HCEC, where it catalyzes the formation of reactive oxygen species (ROS) and induces oxidative DNA lesions as well as DNA strand breaks (indicated by red asterisks). This finally results in cytotoxicity, which is more prominent in HCEC than in CRC cell lines. In contrast, internalized inorganic iron causes little ROS production and DNA damage, and only slightly impairs cell viability. Heme-dependent ROS formation activates the transcription factor Nrf2, which shuttles from the cytoplasm to the nucleus, where it drives the transcription of its target genes such as heme oxygenase-1 (HO-1). This enzyme degrades heme to $\mathrm{Fe}^{2+}$, carbon monoxide (CO) and biliverdin (BV). Concomitant to $\mathrm{HO}-1$ induction, ferritin heavy chain gene (FtH) is upregulated by hemin. Genetic abrogation of HO-1 by siRNA or its pharmacological inhibition by ZnPP potentiated heme-induced ROS, DNA damage and cell death, strongly suggesting that heme iron, and not its breakdown product $\mathrm{Fe}^{2+}$, initiates ROS formation and thus DNA damage induction. $\mathbf{b}$ Internalization of heme iron and inorganic iron in CRC cells. Similar to HCEC, inorganic iron causes little ROS production and DNA damage, and only slightly impairs viability in CRC cells. Hemin is taken up differentially into CRC cells (Caco-2 > HCT116), causing less ROS formation and oxidative DNA damage as in HCEC. Furthermore, CRC cells are in general more resistant against hemin-triggered cytotoxicity and HO-1 abrogation moderately affects cell survival in the presence of high heme concentrations. This figure was created using Servier Medical Art templates, which are licensed under a Creative Commons Attribution 3.0 Unported License; https://smart.servier.com.

strand break induction was previously observed in other CRC cell lines (i.e., Caco-2 and HT29) and in primary colonocytes exposed to hemin at concentrations $\geq 100 \mu \mathrm{M}^{14,34,35}$. DNA strand break formation was also detected in isolated colonocytes from mice fed with red meat $^{36}$. To the best of our knowledge, the present study is the first that demonstrated hemin mediated formation of 8-oxoG in HCEC or CRC cells. Whether or not this occurs also in vivo following dietary heme intake has to be elucidated in future studies. In agreement with the lack of genotoxicity for inorganic iron $\left(\mathrm{Fe}^{2+}\right.$ and $\left.\mathrm{Fe}^{3+}\right)$ observed herein, ferric iron (applied as Fe-NTA) was reported to cause DNA strand breaks only at very high doses $(\geq 500 \mu \mathrm{M})$ in colon adenoma and primary colon cells ${ }^{37}$. This is further supported by the finding that dietary ferric citrate caused significantly lower levels of the DNA strand break marker $\gamma-\mathrm{H} 2 \mathrm{AX}$ in the colon mucosa of $\mathrm{B} 6 / \mathrm{J}$ mice as compared to a diet with $2.5 \%$ hemoglobin ${ }^{18}$.

It has recently been calculated that consumption of 100-500 g red meat (beef) will result in luminal heme concentrations ranging from $17-85 \mu \mathrm{M}$ in humans ${ }^{35}$. Furthermore, data are available from rodent studies, in which the animals were fed with various dietary heme sources (e.g. beef, black pudding, hemin, hemoglobin, processed meat). Heme concentrations between 19-1097 $\mu \mathrm{M}$ were determined in fecal water obtained from the animals ${ }^{16,38,39}$, indicating that high heme concentrations can occur in the large intestine following its dietary uptake. Overall, the heme concentrations used in our study $(20-200 \mu \mathrm{M})$ are in the range of those expected in humans and measured in fecal water from animal feeding studies.

Since ROS formation and DNA damage can both trigger cytotoxic effects, this issue was addressed using different endpoints. On the one hand, our experiments revealed that inorganic iron did neither affect cell cycle distribution nor caused cytotoxicity in HCEC, HCT116 cells and murine intestinal organoids, although being efficiently taken up particularly in HCEC as attested by ICP-MS analysis of the cellular iron content. This is pretty well in line with the observed lack of substantial ROS formation and genotoxicity in our study. On the other hand, hemin was demonstrated to be cytotoxic in a dose-dependent manner in non-malignant HCEC and murine intestinal 
organoids. Interestingly, CRC cell lines were generally more resistant in the order LS174T $>$ HCT116 $>$ Caco- $2 \approx$ RKO. One explanation for these findings could be differences in the cellular uptake efficiency and kinetics of both inorganic iron and heme iron. Ferric iron needs to be reduced for its intestinal uptake, which is catalyzed by ferric reductases such as the duodenal cytochrome B together with reducing compounds (e.g., dietary vitamin C) ${ }^{40}$. Ferrous iron is then mainly internalized by the divalent metal transporter 1 (DMT1) ${ }^{41}$. Screening of the used cell lines by western blot analysis revealed differential DMT1 expression (Supplementary Fig. S5F), with the highest expression levels in Caco-2 and HCT116 cells. HCEC displayed rather low DMT1 expression, but internalization of inorganic iron was better than in HCT116 and Caco- 2 cells. This may be attributable to the required supplementation of the HCEC cell culture medium with transferrin $(2 \mu \mathrm{g} / \mathrm{ml} \approx 25 \mu \mathrm{M})$, which promotes the uptake of ferric iron by receptor-mediated endocytosis. Two pathways were described for the internalization of heme into enterocytes. One pathway seems to involve receptor-mediated endocytosis mediated by a still unknown protein ${ }^{42}$. Moreover, an intestinal heme transporter called HCP-1 was identified ${ }^{4}$, which was also discovered as an intestinal folate transporter in a subsequent study ${ }^{43}$. Western blot detection of HCP-1 in the cell lines used in this study revealed high levels in HCEC and RKO cells, whereas HCT116 and Caco-2 cells displayed only low expression (Supplementary Fig. S4F). Importantly, total cellular iron levels were determined by ICP-MS and showed higher levels in HCEC than in HCT116 cells following incubation with hemin, which could thus be responsibe for the stronger cytotoxic effects observed in HCEC. However, hemin exerted a weaker cytotoxicity in Caco-2 cells despite even higher iron levels as compared to HCEC. Furthermore, RKO cells displayed a moderate sensitivity towards hemin similar to Caco-2 cells, but expressed much higher HCP-1 levels. These findings indicate an involvement of another, HCP-1 independent heme uptake mechanism and highlights the need to measure cellular iron concentrations as done in the present study. It should also be mentioned that intracellular iron levels are further controlled by efflux transporters as described elsewhere ${ }^{7}$.

As the cellular iron levels not directly correlate with the observed cytotoxicity in HCEC and the CRC cell lines, other factors likely contribute to the resistance of CRC cells towards hemin. The tumor suppressor protein $\mathrm{p} 53$, which is activated by genotoxic stress and can trigger cell death, could be considered here given that it is frequently mutated in CRC cells ${ }^{44}$. However, both the resistant HCT116 and LS174T CRC cells as well as the sensitive HCEC express wildtype $\mathrm{p} 53^{45,46}$, thus rather excluding this possibility. Previous studies showed an increased cytotoxicity of fecal water from hemin or hemoglobin fed rodents and its constitiuent 4-HNE in non-transformed murine colonocytes with wildtype $\mathrm{APC}^{17,18}$. Intriguingly, murine colonocytes harboring a mutated APC allel $\left(\mathrm{APC}^{\mathrm{Min} /+}\right)$ were more resistant, which could be due to the higher expression of enzymes implicated in HNE detoxification $^{19}$. Among the human CRC cell lines tested here, LS174T, HCT116 and RKO cells express wildtype APC, while Caco- 2 cells bear APC mutations ${ }^{47,48}$. Thus, no correlation was observed in these cell lines between their sensitivity to hemin and their APC status. Consistent with this finding, murine $\mathrm{APC}^{+/+}$and $\mathrm{APC}^{\mathrm{Min} /+}$ colonocytes displayed similar reduction in viability after treatment with hemin ${ }^{18}$.

Furthermore, we demonstrated that hemin causes Nrf2 stabilization and its translocation into the nucleus of HCEC, which was followed by a robust induction of cytosolic HO-1. In contrast, inorganic iron had little effect on Nrf2 levels and failed to induce HO-1, which goes along with the absence of oxidative stress. A similar upregulation of Nrf2 was detected in murine colonocytes exposed to fecal water from hemoglobin- and beef-fed rats, which was attenuated by former trapping of reactive aldehydes present in fecal water ${ }^{20}$. Further evidence for Nrf2 activation came from a feeding study in mice, which received hemin or ferric citrate as control for up to 14 days. Hemin-fed mice displayed a fast and sustained upregulation of several Nrf2 target genes including catalase, glutathione S-transferase and heme oxygenase $1(\text { Hmox }-1)^{11,49}$. Altogether, these findings emphasize the important role of Nrf2 signaling in response to oxidative stress triggered by heme iron. Furthermore, we showed that hemin also stimulated $\mathrm{FtH}$ expression in a dosedependent manner, which paralleled the induction of $\mathrm{HO}$ 1. FtH is a known Nrf2 target gene ${ }^{50}$ and is also controlled on the translational level by iron-regulatory proteins in a time-dependent manner ${ }^{51}$. Nrf2 is responsible for basal Fth1 expression and induces ferritin expression upon oxidative stress ${ }^{52}$. In line with our findings, hemin was reported to upregulate the expression of $\mathrm{FtH}$ in $\mathrm{K} 562$ human erythroleukemic cells ${ }^{53}$.

To elucidate the role of HO-1 we used $\mathrm{ZnPP}$ as competitive HO-1 inhibitor and, in addition, performed a siRNA-mediated knockdown of HO-1, thereby revealing strongly increased ROS generation and DNA damage induction (i.e. DNA strand breaks, 8-oxoG) in HCEC. This is very likely attributable to the blocked heme catabolism and the concomitant accumulation of intracellular free heme. Genetic or chemical abrogation of HO-1 in HCEC potentiated hemin-dependent cytotoxicity as evidenced by cell viability assays and analysis of cell cycle distribution. Notably, HCT116 cells were almost unaffected after incubation with comparable doses of hemin and ZnPP. Our findings clearly demonstrate a 
cytoprotective role for HO-1 in normal human colonocytes and further indicate that free heme, but not free iron generated following heme catabolism, is mainly responsible for the genotoxic and cytotoxic effects. In this regard, it is important to mention that free iron produced from heme by $\mathrm{HO}-1$ is quickly neutralized by diverse mechanisms, such as the upregulation of $\mathrm{FtH}$ as described above and gene induction of iron efflux pumps ${ }^{24}$. Furthermore, HO-1 mediated degradation of heme generates biliverdin and the gasotransmitter $\mathrm{CO}^{6}$. Biliverdin is transformed into bilirubin by biliverdin reductase, which is known to possess antioxidative activity ${ }^{54}$. $\mathrm{CO}$ is also involved in the cytoprotective effects exerted by HO- $1^{24}$. Interestingly, $\mathrm{HO}-1$ induction and $\mathrm{CO}$ generation were reported to promote the repair of DNA double strand breaks presumably via ATM as shown in $H m o x-1^{-1-}$ mice and fibroblasts derived thereof ${ }^{55}$. These mechanisms could further add to the observed increase in ROS formation and DNA strand break induction in HCEC treated with hemin under HO-1 inhibition. Finally, the cytoprotective function of HO-1 demonstrated here in human colonocytes is consistent with the high ROS levels and decreased survival of Hmox $-1^{-1-}$ embryonic fibroblasts exposed to hemin ${ }^{56}$.

In conclusion, our study provided evidence that free heme iron, but not its breakdown product inorganic iron, plays a pivotal role in ROS formation and DNA damage induction in human colonocytes. HO-1 was further revealed to confer protection against the detrimental effects of hemin. Interestingly, CRC cell lines were generally more resistant to the cytotoxic effects of hemin than normal colonocytes, which might favor the outgrowth of neoplastic cells in vivo and could thereby promote intestinal carcinogenesis.

\section{Material and methods}

\section{Cell culture and treatment}

Non-transformed human colon epithelial cells (HCEC $1 C T)$ were kindly provided by Prof. Jerry W. Shay (Department of Cell Biology, UT Southwestern Medical Center, Dallas, USA). Cells were isolated from normal human colonic biopsies and immortalized by CDK4- and hTERT-transfection as described ${ }^{46}$. HCEC were grown in a nitrogen incubator with reduced oxygen levels $\left(7 \% \mathrm{O}_{2}\right)$ and $5 \% \mathrm{CO}_{2}$ at $37{ }^{\circ} \mathrm{C}$ in 4:1 DMEM GlutaMax/Medium 199 (ThermoFisher Scientific, Darmstadt, Germany). The medium was supplemented with $2 \%$ cosmic calf serum (Hyclone, GE Healthcare, Hamburg, Germany), $25 \mathrm{ng} / \mathrm{ml}$ human epidermal growth factor, $1 \mu \mathrm{g} / \mathrm{ml}$ hydrocortisone, $10 \mu \mathrm{g} / \mathrm{ml}$ insulin from bovine pancreas, $2 \mu \mathrm{g} / \mathrm{ml}$ transferrin, $5 \mathrm{nM}$ sodium selenite and $50 \mu \mathrm{g} / \mathrm{ml}$ gentamycin sulfate (all from Sigma, Schnelldorf, Germany).

HCT116 cells were generously provided by Prof. Bert Vogelstein (John Hopkins University, Baltimore, USA) and obtained from the Core Cell Center (John Hopkins University). RKO cells were a kind gift of Prof. Oliver $\mathrm{H}$. Krämer (Institute of Toxicology, University Medical Center, Mainz, Germany). RKO and HCT116 cells were cultured in DMEM containing $10 \%$ fetal calf serum (FCS) (PanBiotech Aidenbach, Germany) and 1\% penicillin/ streptomycin $(\mathrm{p} / \mathrm{s})$. Caco-2 cells were purchased from CLS Cell Lines Service (Eppelheim, Germany) and maintained in MEM with $10 \%$ FCS, $1 \% \mathrm{p} / \mathrm{s}$ and nonessential amino acids. LS174T cells were a kind gift of Prof. Thomas Brunner (University of Konstanz, Konstanz, Germany) and cultured in IMDM medium (Pan Biotech, Aidenbach, Germany) with 10\% FCS and 1\% p/s. CRC cell lines were maintained at $37^{\circ} \mathrm{C}$ in a humidified atmosphere of $5 \% \mathrm{CO}_{2}$ under standard culture conditions $\left(\sim 20 \% \mathrm{O}_{2}\right)$. For selected experiments, CRC cells were cultured under hypoxic conditions $\left(7 \% \mathrm{O}_{2}\right)$ in the nitrogen incubator. Cell culture medium and supplements were obtained from Life Technologies (Darmstadt, Germany) unless stated otherwise. Cell lines were mycoplasma negative as demonstrated by PCR and immunofluorescence microscopy with nuclear staining. All cell lines were authenticated as described previously ${ }^{57,58}$.

Hemin $\left(\mathrm{Fe}^{3+}\right.$ protoporphyrin IX chloride; Sigma, Schnelldorf, Germany) was dissolved in $20 \mathrm{mM}$ sodium hydroxide $(\mathrm{NaOH})$, while ferric chloride $\left(\mathrm{FeCl}_{3}\right)$ and ferrous sulfate $\left(\mathrm{FeSO}_{4}\right)$, both purchased at Sigma, were dissolved in water to obtain stock concentrations of $1 \mathrm{mM}$ each. Zinc protoporphyrin (ZnPP; Enzo Life Science, Farmingdale, USA) was dissolved in DMSO at a final concentration of $5 \mathrm{mM}$.

\section{Transient transfection with siRNA tageting HO-1}

Knockdown of HO-1 was performed using siGENOME SMARTpool siRNA from Dharmacon (Lafayette, USA). Cells grown in 6 well or 96 well plates were transfected at $40 \%$ confluency with $20 \mathrm{nM}$ siRNA using Lipofectamine ${ }^{\circledR}$ RNAimax (Invitrogen, Darmstadt, Germany). Scrambled, non-sense siRNA ( $20 \mathrm{nM}$; Dharmacon, Lafayette, USA) was included as negative control. $24 \mathrm{~h}$ after transfection, cells were treated with hemin for different incubation periods and analyzed as indicated. HO-1 knockdown was checked by SDS-PAGE and western blot detection.

\section{Generation of murine intestinal organoids and assessment of viability}

Isolation of intestinal crypts, ex vivo culture and expansion to intestinal organoids were essentially performed as described ${ }^{59}$. C57BL6/J mice (8-12 weeks) were sacrificed followed by the preparation of the small intestine. The organ was opened longitudinally and cut into $1-2 \mathrm{~cm}$ pieces after villi had been scraped off with a microscope slide. The tissue slices were washed with icecold PBS and then incubated in PBS containing $2 \mathrm{mM}$ 
EDTA for $30 \mathrm{~min}$ at $4{ }^{\circ} \mathrm{C}$ on a rotator. Subsequently, PBS/ EDTA was removed and replaced by PBS. After gentle shaking, the supernatant was monitored by light microscopy for residual villi and containing crypts. This process was repeated until the villi/crypt ratio in the supernatant was optimal, showing the highest number of intact crypts. The suspension was then filtered through a $70 \mu \mathrm{m}$ cell strainer (BD Biosciences, Heidelberg, Germany) to remove residual villi, pelleted by centrifugation and crypts were resuspended in PBS for counting. After another centrifugation step, crypts were resuspendend in Matrigel (BD Biosciences) at the desired density (typically 100-300 crypts per $8 \mu \mathrm{l}$ of Matrigel). Crypts were seeded into a flat bottom 96 well plate by applying a droplet of $8 \mu$ l Matrigel to each well, which was allowed to polymerize at $37^{\circ} \mathrm{C}$ for $30 \mathrm{~min}$. Afterwards, $80 \mu \mathrm{l}$ of complete crypt culture medium was added consisting of advanced DMEM/F12, $10 \mathrm{mM}$ HEPES, $100 \mathrm{U} / \mathrm{ml}$ penicillin, $100 \mathrm{mg} / \mathrm{ml}$ streptomycin, $20 \mathrm{mg} / \mathrm{ml}$ nystatin, $1 \mathrm{mM} \mathrm{N}$-acetyl cysteine (all from Sigma, Schnelldorf, Germany), 0.1\% BSA (Carl Roth, Karlsruhe, Germany), $2 \mathrm{mM}$ L-glutamine, $1 \mathrm{x}$ B27 supplement, 1x N2 supplement (all from Life Technologies, Darmstadt, Germany), $50 \mathrm{ng} / \mathrm{ml}$ murine EGF, $100 \mathrm{ng} / \mathrm{ml}$ murine Noggin and $500 \mathrm{ng} / \mathrm{ml}$ human Rspondin-1 (all from Peprotech, Hamburg, Germany). Intestinal organoids were maintained at $37^{\circ} \mathrm{C}$ and $5 \% \mathrm{CO}_{2}$ in the incubator for 3 days. Organoids were then exposed to increasing concentrations of hemin or ferric chloride $(0-100 \mu \mathrm{M})$ for $24 \mathrm{~h}$. Viability was determined using the MTT assay. To this end, MTT solution was added to the organoid culture at a final concentration of $500 \mu \mathrm{g} / \mathrm{ml}$. After an incubation for $1 \mathrm{~h}$, the medium was discarded and $20 \mu \mathrm{l}$ of $2 \%$ SDS solution was added in order to solubilize the Matrigel. After another $1 \mathrm{~h}$ of incubation, the solution was discarded and the reduced MTT was solubilized with $80 \mu \mathrm{l}$ DMSO for $1 \mathrm{~h}$. Absorbance at $562 \mathrm{~nm}$ was determined using a microplate reader (Sunrise Tecan Reader, Crailsheim, Germany). Solvent treated organoids were defined as $100 \%$ viable.

\section{Determination of cell viability by ATP and MTS assay}

Viability of CRC cells and HCEC was determined using the Cell Titer 96® AQueous One Solution Cell Proliferation Assay (Promega, Mannheim, Germay) as reported $^{58}$. Cells (HCT116: $5 \times 10^{3} /$ well; Caco-2: $5 \times 10^{3} /$ well; LS174T: $5 \times 10^{3} /$ well, RKO: $5 \times 10^{3} /$ well and HCEC: $1 \times 10^{3} /$ well) were grown overnight and then treated with increasing concentrations of hemin or iron chloride $\left(0-200 \mu \mathrm{M}\right.$ as indicated). $\mathrm{NaOH}$ or $\mathrm{H}_{2} \mathrm{O}$ served as respective solvent controls. After $72 \mathrm{~h}$, viability was measured using a microplate reader (Sunrise Tecan Reader, Crailsheim, Germany) according to the manufacturer's instructions. To analyze the effects of hemin in the absence or presence of the HO-1 inhibitor $\mathrm{ZnPP}$,
HCT116 cells $\left(24 \mathrm{~h}: 1.5 \times 10^{4}\right.$ cells/well; $72 \mathrm{~h}: 5 \times 10^{3}$ cells/ well) or $\operatorname{HCEC~(~} 24 \mathrm{~h}: 2.5 \times 10^{3} /$ well; $72 \mathrm{~h}: 1 \times 10^{3} /$ well) were grown in white 96 -well plates overnight. Cells were then preincubated with $\mathrm{ZnPP}(0-2.5 \mu \mathrm{M})$ for $1 \mathrm{~h}$ followed by the addition of hemin $(0-100 \mu \mathrm{M})$. Viability was assessed after 24 or $72 \mathrm{~h}$ using the MTS assay as described above. Furthermore, viability was determined with the CellTiter-Glo®Luminescent Cell Viability Assay (Promega, Mannheim, Germany), which measures the cellular ATP level. The assay was performed according to the manufacturer's instructions with a MicroLumat Plus 96well plate reader (Berthold, Bad Wildbad, Germany).

\section{ICP-MS analysis to determine total cellular iron levels}

Caco- 2 cells $\left(1 \times 10^{5}\right)$, HCT116 cells $\left(5 \times 10^{5}\right)$ or HCEC $\left(2 \times 10^{5}\right)$ were grown in $6 \mathrm{~cm}$ dishes and treated with hemin or ferric chloride for $0.25,1,8$ and $24 \mathrm{~h}$. Cells were trypsinized and harvested by centrifugation. The pellets were then digested in $0.5 \mathrm{ml} \mathrm{H}_{2} \mathrm{O}_{2} / \mathrm{HNO}_{3}$ (1:1) overnight at $95{ }^{\circ} \mathrm{C}$. The residue was dissolved in $1.5 \mathrm{ml} 10 \% \mathrm{HNO}_{3}$ with $0.5 \mu \mathrm{g} / \mathrm{l} \mathrm{Rh}$ (Merck, Darmstadt, Germany) as internal standard and diluted if required. Quantification was performed with an external calibration curve ranging from 0.5-100 $\mu \mathrm{g} / \mathrm{l} \mathrm{Fe}$ (Spetec, Erding, Germany). The measurements were conducted with a tandem mass spectrometer (8800 triple quadrupole ICP-MS, Agilent Technologies, Böblingen, Germany) equipped with two quadrupols (Q1 and Q2) as well as a collision and reaction cell with $\mathrm{O}_{2}(0.3 \mathrm{ml} / \mathrm{min})$ as collision gas. Quantification was carried out directly using the ${ }^{56} \mathrm{Fe}^{+}$ion (Q1 and Q2 mass-to-charge $(\mathrm{m} / \mathrm{z})$ ratio 56$)$ or indirectly using the ${ }^{56} \mathrm{Fe}^{16} \mathrm{O}^{+}$ion (Q1 m/z 56 and Q2 m/z 72).

\section{SDS-PAGE and Western blot}

HCT116 cells $\left(3 \times 10^{5}\right)$ or HCEC $\left(2 \times 10^{5}\right)$ were seeded in $3.5 \mathrm{~cm}$ dishes and allowed to adhere overnight. Following treatment with hemin or ferric chloride as indicated, cells were harvested in 1× Lämmli loading buffer. Western blot analysis was essentially performed as described $^{57}$. Equal protein amounts were separated by SDS-PAGE followed by transfer onto a nitrocellulose membrane (Amersham ${ }^{\mathrm{TM}}$ Protran ${ }^{\circledR}, \mathrm{GE}$ Healthcare, Freiburg, Germany) with a wet blot chamber (BioRad, München, Germany). Membranes were then blocked with $5 \%$ nonfat dry milk (Carl Roth) in Tris-buffered saline (TBS) $/ 0.1 \%$ Tween-20 for $1 \mathrm{~h}$ at RT. Primary antibody incubation was conducted overnight at $4{ }^{\circ} \mathrm{C}$ followed by three washing steps $(3 \times 5 \mathrm{~min})$ in $\mathrm{TBS} / 0.1 \%$ Tween-20. Membranes were then incubated with appropriate secondary antibodies for at least $1 \mathrm{~h}$ at RT. After $3 \times 5 \mathrm{~min}$ washing, proteins were detected using Western Lightning ${ }^{\circledR}$ Plus-ECL (Perkin Elmer, Rodgau, Germany). The following primary antibodies anti-ferritin heavy chain gene (FtH; mouse monoclonal, B-12; no. sc-376594), 
anti-heat shock protein 90 (Hsp90) $\alpha / \beta$ (mouse monoclonal; no. sc-13119), anti-heme carrier protein-1 (HCP-1; B-4; mouse monoclonal; no. sc-393460) were all purchased from Santa Cruz Biotechnology, Heidelberg, Germany. The primary antibodies anti-divalent metal transporter-1 (DMT1; rabbit polyclonal; no. GTX64686), anti-heme oxygenase-1 (HO-1; rabbit polyclonal; no. GTX101147) and anti-nuclear factor E2-related factor (Nrf2; rabbit monoclonal; no. GTX103322) were obtained from GeneTex, Irvine, California, USA. Secondary antibodies conjugated with horseradish-peroxidase were from Santa Cruz (anti-mouse) and Cell Signaling (anti-rabbit).

\section{Measurement of ROS formation by flow cytometry}

HCT116 cells $\left(3 \times 10^{5} /\right.$ well $)$, Caco- 2 cells $\left(2 \times 10^{5} /\right.$ well $)$ and HCEC $\left(2 \times 10^{5} /\right.$ well $)$ were grown overnight in six-well plates. Cells were treated with increasing doses of hemin or ferric chloride $(0-200 \mu \mathrm{M})$ for up to $24 \mathrm{~h}$. Incubation with $200 \mu \mathrm{M} \mathrm{H}_{2} \mathrm{O}_{2}$ (Merck, Darmstadt, Germany) for 20 min in PBS served as positive control. Levels of reactive oxygen species (ROS) were determined as reported ${ }^{60}$. Briefly, cells were rinsed twice with pre-warmed PBS and then were loaded with $2.5 \mu \mathrm{M}$ CM-H2DCFDA (Invitrogen, Darmstadt, Germany) for $30 \mathrm{~min}$ at $37^{\circ} \mathrm{C}$ using phenol red-and serum-free medium. Following a washing step with PBS, cells were harvested using Trypsin/EDTA, pelleted by centrifugation and resuspended in PBS. Finally, cells were analyzed by flow cytometry using a BD FACSCanto II (BD Biosciences, Heidelberg, Germany) and evaluated using BD FACSDiva software.

\section{Assessment of cell cycle distribution by flow cytometry}

Cell cycle analysis was performed as described ${ }^{61}$. HCT116 cells $\left(5 \times 10^{5}\right)$ and HCEC $\left(3 \times 10^{5}\right)$ were grown overnight in $6 \mathrm{~cm}$ dishes and then exposed to increasing doses of hemin or ferric chloride in the presence or absence of $\mathrm{ZnPP}$ as indicated. After $24 \mathrm{~h}$ of incubation, cells were harvested and washed twice in PBS. Following ethanol precipitation at $-20^{\circ} \mathrm{C}$ for $1 \mathrm{~h}$, the pellet was resuspended in PBS containing RNase A $(20 \mu \mathrm{g} / \mathrm{ml})$ and incubated for $1 \mathrm{~h}$ at RT. Subsequently, propidium iodide (PI; Sigma) was added to a final concentration of $10 \mu \mathrm{g} /$ $\mathrm{ml}$, and cells were analyzed for DNA content by flow cytometry using BD FACSCanto II (BD Biosciences). Cell cycle distribution was analyzed with BD FACSDiva software.

\section{Detection of DNA damage by the Comet assay}

HCT116 cells $\left(2.5 \times 10^{5}\right)$ and HCEC $\left(1.5 \times 10^{5}\right)$ were seeded in $3.5 \mathrm{~cm}$ dishes and grown overnight. Cells were then incubated with increasing concentrations of hemin or ferric chloride for 2 or $24 \mathrm{~h}$ as stated. As positive control, the cells were treated with $50 \mu \mathrm{M}$ tert-butyl hydroperoxide (t-BOOH; Sigma) for $20 \mathrm{~min}$. Cells were then harvested and processed for the alkaline Comet assay as described $^{62,63}$. Cells embedded in $0.5 \%$ low melting point agarose were transferred onto a slide pre-coated with agarose. The slides were incubated for $1 \mathrm{~h}$ in lysis buffer consisting of $2.5 \mathrm{M}$ sodium chloride $(\mathrm{NaCl}), 100 \mathrm{mM}$ ethyldiamine tetraacetic acid (EDTA), 1\% Triton X-100 and $10 \mathrm{mM}$ Tris $\mathrm{pH} 10$. As a next step, DNA unwinding was conducted in electrophoresis buffer $(300 \mathrm{mM} \mathrm{NaOH}, 1 \mathrm{mM}$ EDTA pH 13) for $25 \mathrm{~min}$ at $4{ }^{\circ} \mathrm{C}$. Samples were then subjected to electrophoresis for $15 \mathrm{~min}$ at $25 \mathrm{~V}$ and $300 \mathrm{~mA}$ followed by a neutralization step with $0.4 \mathrm{M}$ Tris $\mathrm{pH} 7.5$. After fixation in $100 \%$ ethanol, the air-dried samples were stained with $50 \mu \mathrm{g} / \mathrm{ml}$ PI (Sigma). Comets were analyzed by fluorescence microscopy using an Olympus BX50 microscope equipped with a ColorView camera (Olympus, Münster, Germany). In each experiment, at least 50 cells were scored using Comet IV software (Perceptive Instruments Ltd., Bury St Edmunds, UK).

To detect oxidative DNA damage (i.e., 8-Oxoguanine), the Formamidopyrimidine-DNA glycosylase (Fpg)-modified alkaline Comet assay was used ${ }^{64}$. After cell lysis, the slides were incubated in a buffer containing Fpg $(1 \mu \mathrm{g} / \mathrm{ml})$, $40 \mathrm{mM}$ HEPES, $0.1 \mathrm{M} \mathrm{KCL}, 0.5 \mathrm{mM}$ EDTA and $0.2 \mathrm{mg} / \mathrm{ml}$ BSA, pH 8.0 for $37 \mathrm{~min}$ at $37^{\circ} \mathrm{C}$. Subsequently, the protocol was continued with the DNA unwinding step as described above.

\section{Confocal microscopy of fixed cells}

HCEC $\left(1 \times 10^{5}\right.$ cells) were seeded on coverslips in 6-well plates. After $24 \mathrm{~h}, \mathrm{HCEC}$ were treated with increasing doses of hemin $(0-100 \mu \mathrm{M})$ and incubated for $8 \mathrm{~h}$. Immunofluorescence staining was performed as reported ${ }^{65}$. Upon fixation with methanol at $-20^{\circ} \mathrm{C}$ for $10 \mathrm{~min}$, cells were washed twice with PBS and then incubated for $1 \mathrm{~h}$ with blocking solution consisting of $5 \%$ bovine serum albumin (BSA) in PBS with $0.3 \%$ Triton X-100. The samples were incubated with an anti-Nrf2 antibody (Genetex; diluted 1:500 in PBS/0.2\% Triton X-100) or an anti-HO1 antibody (Genetex; diluted 1:1,000 in PBS/0.2\% Triton X-100) overnight at $4{ }^{\circ} \mathrm{C}$. After several washing steps, the samples were incubated with an appropriate Alexa488-coupled goat-anti-rabbit secondary antibody (Life Technologies; 1:400 in PBS plus 0.2\% Triton X-100). Nuclei were finally counterstained using TO-PRO-3 (Life Technologies; 1:100 in PBS). Coverslips were mounted using VectaShield (Vector Labs, Burlingame, USA) and analyzed with a Zeiss Axio Observer.Z1 microscope equipped with a confocal LSM710 laser-scanning unit (Zeiss, Oberkochen, Germany). Pictures were analyzed and processed using Image J.

\section{Cell fractionation}

Cells were treated as indicated and subjected to cell fractionation according to a protocol published 
recently ${ }^{65}$. Protein content of the cytoplasmic and nuclear fractions was determined by the Bradford assay. SDS-PAGE and Western blot analysis were conducted as described above.

\section{Statistics}

Experiments were performed independently three times, except when otherwise stated. Representative experiments are displayed. Values are presented as means + standard error of the means (SEM). Data were analyzed for outliers with the Grubbs' test using GraphPad Prism 7.0 software. Statistical analysis was then performed in GraphPad Prism using two-sided Student's $t$-test and statistical significance was defined as $p<0.05$.

\section{Acknowledgements}

We thank Anna Frumkina (Department of Toxicology, University Medical Center Mainz, Germany) for performing the alkaline Comet assay. We are grateful to Prof. Bert Vogelstein (John Hopkins University, Baltimore, USA) for providing HCT116 cells and to Prof. Jerry W. Shay (University of Texas Southwestern Medical Center, Dallas, USA) for providing HCEC. Fpg enzyme was a kind gift of Prof. Bernd Epe (University of Mainz, Germany). This work was supported by the University Medical Center Mainz (Stufe I), the German Research Foundation (DFG-FA1034/3-3) and the DFG funded research unit TraceAge (FOR 2558). Open access funding provided by Projekt DEAL.

\section{Author details \\ 'Department of Toxicology, University Medical Center, Mainz, Germany. ${ }^{2}$ Rudolf Buchheim Institute of Pharmacology, Justus Liebig University Giessen, Giessen, Germany. ${ }^{3}$ Division of Food Chemistry and Toxicology, Department of Chemistry, Technical University of Kaiserslautern, Kaiserslautern, Germany. ${ }^{4}$ Department of Food Chemistry, Institute of Nutritional Science, University of Potsdam, Nuthetal, Germany. ${ }^{5}$ TraceAge - DFG Research Unit on Interactions of Essential Trace Elements in Healthy and Diseased Elderly (FOR 2558), Berlin- Potsdam-Jena, Germany. ${ }^{6}$ Biochemical Pharmacology, Department of Biology, University of Konstanz, Konstanz, Germany. ${ }^{7}$ Present address: Department of Pharmacology, University Medical Center, Mainz, Germany}

\section{Conflict of interest}

The authors declare no conflict of interest.

\section{Publisher's note}

Springer Nature remains neutral with regard to jurisdictional claims in published maps and institutional affiliations.

Supplementary Information accompanies this paper at (https://doi.org/ 10.1038/s41419-020-02950-8).

Received: 1 April 2020 Revised: 20 August 2020 Accepted: 27 August 2020 Published online: 23 September 2020

\section{References}

1. Hurrell, R. \& Egli, I. Iron bioavailability and dietary reference values. Am. J. Clin. Nutr. 91, 1461S-1467S (2010).

2. Reedy, C. J. \& Gibney, B. R. Heme protein assemblies. Chem. Rev. 104, 617-649 (2004).

3. Hooda, J., Shah, A. \& Zhang, L. Heme, an essential nutrient from dietary proteins, critically impacts diverse physiological and pathological processes. Nutrients 6, 1080-1102 (2014).

4. Shayeghi, M. et al. Identification of an intestinal heme transporter. Cell $\mathbf{1 2 2}$ 789-801 (2005).

5. Latunde-Dada, G. O., Takeuchi, K., Simpson, R. J. \& McKie, A. T. Haem carrier protein 1 (HCP1): expression and functional studies in cultured cells. FEBS Lett. 580, 6865-6870 (2006).
6. Montellano, P. R. The mechanism of heme oxygenase. Curr. Opin. Chem. Biol. 4, 221-227 (2000).

7. Seiwert, N., Heylmann, D., Hasselwander, S. \& Fahrer, J. Mechanism of colorectal carcinogenesis triggered by heme iron from red meat. Biochim. Biophys. Acta Rev. Cancer 1873, 188334 (2020).

8. Lombardi-Boccia, G., Martinez-Dominguez, B. \& Aguzzi, A. Total heme and non-heme iron in raw and cooked meats. J. Food Sci. 67, 1737-1741 (2002).

9. Bouvard, V. et al. Carcinogenicity of consumption of red and processed meat. Lancet Oncol. 16, 1599-1600 (2015).

10. Brookes, M. J. et al. A role for iron in Wnt signalling. Oncogene $\mathbf{2 7}$, 966-975 (2008).

11. IJssennagger, N. et al. Dietary haem stimulates epithelial cell turnover by downregulating feedback inhibitors of proliferation in murine colon. Gut 61, 1041-1049 (2012).

12. ljssennagger, N. et al. Gut microbiota facilitates dietary heme-induced epithelial hyperproliferation by opening the mucus barrier in colon. Proc. Natl Acad. Sci. USA 112, 10038-10043 (2015).

13. Constante, M., Fragoso, G., Calve, A., Samba-Mondonga, M. \& Santos, M. M. Dietary heme induces gut dysbiosis, aggravates colitis, and potentiates the development of adenomas in mice. Front. Microbiol. 8, 1809 (2017).

14. Glei, M. et al. Hemoglobin and hemin induce DNA damage in human colon tumor cells HT29 clone 19A and in primary human colonocytes. Mutat. Res. 594, 162-171 (2006).

15. Winter, J. et al. Inhibition by resistant starch of red meat-induced promutagenic adducts in mouse colon. Cancer Prev. Res. 4, 1920-1928 (2011).

16. Sesink, A. L., Termont, D. S., Kleibeuker, J. H. \& Van der Meer, R. Red meat and colon cancer: the cytotoxic and hyperproliferative effects of dietary heme. Cancer Res. 59, 5704-5709 (1999).

17. Pierre, F. et al. Apc mutation induces resistance of colonic cells to lipoperoxide-triggered apoptosis induced by faecal water from haem-fed rats. Carcinogenesis 28, 321-327 (2007).

18. Bastide, N. M. et al. A central role for heme iron in colon carcinogenesis associated with red meat intake. Cancer Res. 75, 870-879 (2015).

19. Baradat, M. et al. 4-Hydroxy-2(E)-nonenal metabolism differs in $\mathrm{Apc}(+/+)$ cells and in $\operatorname{Apc}(\mathrm{Min} /+)$ cells: it may explain colon cancer promotion by heme iron. Chem. Res. Toxicol. 24, 1984-1993 (2011).

20. Surya, R. et al. Red meat and colorectal cancer: Nrf2-dependent antioxidant response contributes to the resistance of preneoplastic colon cells to fecal water of hemoglobin- and beef-fed rats. Carcinogenesis 37, 635-645 (2016).

21. Tebay, L. E. et al. Mechanisms of activation of the transcription factor Nrf2 by redox stressors, nutrient cues, and energy status and the pathways through which it attenuates degenerative disease. Free Radic. Biol. Med. 88, 108-146 (2015).

22. Hamm, M. L., Gill, T. J., Nicolson, S. C. \& Summers, M. R. Substrate specificity of Fpg (MutM) and hOGG1, two repair glycosylases. J. Am. Chem. Soc. 129, 7724-7725 (2007)

23. Loboda, A., Damulewicz, M., Pyza, E., Jozkowicz, A. \& Dulak, J. Role of Nrf2/HO1 system in development, oxidative stress response and diseases: an evolutionarily conserved mechanism. Cell Mol. Life Sci. 73, 3221-3247 (2016).

24. Gozzelino, R., Jeney, V. \& Soares, M. P. Mechanisms of cell protection by heme oxygenase-1. Annu. Rev. Pharm. Toxicol. 50, 323-354 (2010).

25. Tonelli, C., Chio, I. I. C. \& Tuveson, D. A. Transcriptional Regulation by Nrf2. Antioxid. Redox Signal 29, 1727-1745 (2018).

26. Neitzel, C. et al. Lipoic acid synergizes with antineoplastic drugs in colorectal cancer by targeting p53 for proteasomal degradation. Cells 8, 794 (2019).

27. Reichard, J. F., Motz, G. T. \& Puga, A. Heme oxygenase-1 induction by NRF2 requires inactivation of the transcriptional repressor BACH1. Nucleic Acids Res. 35, 7074-7086 (2007)

28. Zenke-Kawasaki, Y. et al. Heme induces ubiquitination and degradation of the transcription factor Bach1. Mol. Cell Biol. 27, 6962-6971 (2007).

29. Sahoo, S. K. et al. Pegylated zinc protoporphyrin: a water-soluble heme oxygenase inhibitor with tumor-targeting capacity. Bioconjug. Chem. 13, 1031-1038 (2002)

30. Knöbel, Y., Glei, M., Osswald, K. \& Pool-Zobel, B. L. Ferric iron increases ROS formation, modulates cell growth and enhances genotoxic damage by 4-hydroxynonenal in human colon tumor cells. Toxicol. Vitr. 20, 793-800 (2006).

31. Persson, H. L., Vainikka, L. K., Eriksson, I. \& Wennerstrom, U. TNF-alphastimulated macrophages protect A549 lung cells against iron and oxidation. Exp. Toxicol. Pathol. 65, 81-89 (2013). 
32. Li, S. W. et al. Iron overload induced by ferric ammonium citrate triggers reactive oxygen species-mediated apoptosis via both extrinsic and intrinsic pathways in human hepatic cells. Hum. Exp. Toxicol. 35, 598-607 (2016).

33. Kim, H., Yin, K., Falcon, D. M. \& Xue, X. The interaction of Hemin and Sestrin2 modulates oxidative stress and colon tumor growth. Toxicol. Appl Pharm. $\mathbf{3 7 4}$ 77-85 (2019).

34. Ishikawa, S., Tamaki, S., Ohata, M., Arihara, K. \& Itoh, M. Heme induces DNA damage and hyperproliferation of colonic epithelial cells via hydrogen peroxide produced by heme oxygenase: a possible mechanism of heme-induced colon cancer. Mol. Nutr. Food Res. 54, 1182-1191 (2010).

35. Kostka, T. et al. Synthesis and in vitro characterization of the genotoxic, mutagenic and cell-transforming potential of nitrosylated heme. Arch. Toxicol. https://doi.org/10.1007/s00204-020-02846-8 (2020).

36. Toden, S., Bird, A. R., Topping, D. L. \& Conlon, M. A. High red meat diets induce greater numbers of colonic DNA double-strand breaks than white meat in rats: attenuation by high-amylose maize starch. Carcinogenesis 28, 2355-2362 (2007).

37. Knöbel, Y. et al. Ferric iron is genotoxic in non-transformed and preneoplastic human colon cells. Food Chem. Toxicol. 45, 804-811 (2007).

38. Pierre, F., Freeman, A., Tache, S., Van der Meer, R. \& Corpet, D. E. Beef meat and blood sausage promote the formation of azoxymethane-induced mucindepleted foci and aberrant crypt foci in rat colons. J. Nutr. 134, 2711-2716 (2004).

39. Santarelli, R. L. et al. Meat processing and colon carcinogenesis: cooked, nitritetreated, and oxidized high-heme cured meat promotes mucin-depleted foci in rats. Cancer Prev. Res. 3, 852-864 (2010).

40. McKie, A. T. et al. An iron-regulated ferric reductase associated with the absorption of dietary iron. Science 291, 1755-1759 (2001).

41. Fleming, M. D. et al. Microcytic anaemia mice have a mutation in Nramp2, a candidate iron transporter gene. Nat. Genet. 16, 383-386 (1997).

42. Grasbeck, R., Kouvonen, I., Lundberg, M. \& Tenhunen, R. An intestinal receptor for heme. Scand. J. Haematol. 23, 5-9 (1979).

43. Qiu, A. et al. Identification of an intestinal folate transporter and the molecular basis for hereditary folate malabsorption. Cell 127, 917-928 (2006).

44. Liu, Y. \& Bodmer, W. F. Analysis of P53 mutations and their expression in 56 colorectal cancer cell lines. Proc. Natl Acad. Sci. USA 103, 976-981 (2006).

45. Ahmed, D. et al. Epigenetic and genetic features of 24 colon cancer cell lines. Oncogenesis 2, e71 (2013).

46. Roig, A. I. et al. Immortalized epithelial cells derived from human colon biopsies express stem cell markers and differentiate in vitro. Gastroenterology 138, 1012-1021 e1011-1015 (2010).

47. da Costa, L. T. et al. CDX2 is mutated in a colorectal cancer with normal APC/ beta-catenin signaling. Oncogene 18, 5010-5014 (1999).

48. Rowan, A. J. et al. APC mutations in sporadic colorectal tumors: a mutational "hotspot" and interdependence of the "two hits". Proc. Natl Acad. Sci. USA 97, 3352-3357 (2000)
49. IJssennagger, $\mathrm{N}$. et al. Dietary heme induces acute oxidative stress, but delayed cytotoxicity and compensatory hyperproliferation in mouse colon Carcinogenesis 34, 1628-1635 (2013).

50. Thimmulappa, R. K. et al. Identification of Nrf2-regulated genes induced by the chemopreventive agent sulforaphane by oligonucleotide microarray. Cancer Res. 62, 5196-5203 (2002)

51. Tsuji, Y. et al. Coordinate transcriptional and translational regulation of ferritin in response to oxidative stress. Mol. Cell Biol. 20, 5818-5827 (2000).

52. Pietsch, E. C., Chan, J. Y., Torti, F. M. \& Torti, S. V. Nrf2 mediates the induction of ferritin $\mathrm{H}$ in response to xenobiotics and cancer chemopreventive dithiolethiones. J. Biol. Chem. 278, 2361-2369 (2003).

53. Iwasaki, K., Mackenzie, E. L., Hailemariam, K., Sakamoto, K. \& Tsuji, Y. Heminmediated regulation of an antioxidant-responsive element of the human ferritin $\mathrm{H}$ gene and role of Ref-1 during erythroid differentiation of K562 cells. Mol. Cell Biol. 26, 2845-2856 (2006).

54. Stocker, R., Yamamoto, Y., McDonagh, A. F., Glazer, A. N. \& Ames, B. N. Bilirubin is an antioxidant of possible physiological importance. Science 235, 1043-1046 (1987).

55. Otterbein, L. E. et al. Heme oxygenase-1 and carbon monoxide modulate DNA repair through ataxia-telangiectasia mutated (ATM) protein. Proc. Natl Acad. Sci. USA 108, 14491-14496 (2011).

56. Poss, K. D. \& Tonegawa, S. Reduced stress defense in heme oxygenase 1deficient cells. Proc. Natl Acad. Sci. USA 94, 10925-10930 (1997).

57. Mimmler, M. et al. DNA damage response curtails detrimental replication stress and chromosomal instability induced by the dietary carcinogen PhIP. Nucleic Acids Res. 44, 10259-10276 (2016).

58. Seiwert, N. et al. AKT2 suppresses pro-survival autophagy triggered by DNA double-strand breaks in colorectal cancer cells. Cell Death Dis. 8 , e3019 (2017).

59. Grabinger, T., Delgado, E. \& Brunner, T. Analysis of cell death induction in intestinal organoids in vitro. Methods Mol. Biol. 1419, 83-93 (2016).

60. Dörsam, B., Wu, C. F., Efferth, T., Kaina, B. \& Fahrer, J. The eucalyptus oil ingredient 1,8-cineol induces oxidative DNA damage. Arch. Toxicol. 89 797-805 (2015).

61. Dörsam, B., Göder, A., Seiwert, N., Kaina, B. \& Fahrer, J. Lipoic acid induces p53independent cell death in colorectal cancer cells and potentiates the cytotoxicity of 5-fluorouracil. Arch. Toxicol. 89, 1829-1846 (2015).

62. Fahrer, J. et al. Cytolethal distending toxin (CDT) is a radiomimetic agent and induces persistent levels of DNA double-strand breaks in human fibroblasts. DNA Repair 18, 31-43 (2014).

63. Dörsam, B. et al. PARP-1 protects against colorectal tumor induction, but promotes inflammation-driven colorectal tumor progression. Proc. Natl Acad. Sci. USA 115, E4061-E4070 (2018).

64. Mikhed, Y. et al. Nitroglycerin induces DNA damage and vascular cell death in the setting of nitrate tolerance. Basic Res Cardiol. 111, 52 (2016).

65. Göder, A. et al. Lipoic acid inhibits the DNA repair protein O6-methylguanineDNA methyltransferase (MGMT) and triggers its depletion in colorectal cancer cells with concomitant autophagy induction. Carcinogenesis 36, 817-831 (2015). 